\title{
Artificial Intelligence and Reduced SMEs' Business Risks. A Dynamic Capabilities Analysis During the COVID-19 Pandemic
}

\author{
Nick Drydakis ${ }^{1,2,3,4,5}$
}

Accepted: 19 January 2022 / Published online: 4 March 2022

(c) The Author(s), under exclusive licence to Springer Science+Business Media, LLC, part of Springer Nature 2022

\begin{abstract}
The study utilises the International Labor Organization's SMEs COVID-19 pandemic business risks scale to determine whether Artificial Intelligence (AI) applications are associated with reduced business risks for SMEs. A new 10-item scale was developed to capture the use of AI applications in core services such as marketing and sales, pricing and cash flow. Data were collected from 317 SMEs between April and June 2020, with follow-up data gathered between October and December 2020 in London, England. AI applications to target consumers online, offer cash flow forecasting and facilitate HR activities are associated with reduced business risks caused by the COVID-19 pandemic for both small and medium enterprises. The study indicates that AI enables SMEs to boost their dynamic capabilities by leveraging technology to meet new types of demand, move at speed to pivot business operations, boost efficiency and thus, reduce their business risks.
\end{abstract}

Keywords SMEs · Business Risks · COVID-19 pandemic $\cdot$ Artificial Intelligence $\cdot$ Dynamic Capabilities

\section{Introduction}

SMEs have transformed to succeed in the emerging digital world (Chan, Morgan, et al., 2018; Chan, Teoh, et al., 2018; Ulas, 2019). Indeed, digital technologies aided by Artificial Intelligence (AI) have transformed the nature and scope of entrepreneurial activity in SMEs (Hansen \& Bøgh, 2021; Ulas, 2019). It has been shown that SMEs that adopt digital technology aided by AI enhance their competitive advantage and productivity (Chan et al., 2018; Chan, Morgan, et al., 2018; Kumar \& Kalse, 2021). SMEs invest in AI technologies to track users' habits and provide recommendations, improve customer's purchasing decisions, search

Nick Drydakis

nick.drydakis@aru.ac.uk

1 School of Economics, International Business and Law, Centre for Pluralist Economics, Faculty of Business and Law, Anglia Ruskin University, East Road, Cambridge, CB 1 1PT, UK

2 Pembroke College, University of Cambridge, Cambridge, UK

3 Centre for Science and Policy, University of Cambridge, Cambridge, UK

4 Global Labor Organization, Essen, Germany

5 Institute for Labor Economics, Bonn, Germany results, media communication, trade raise sales, improve organisational performance, and lower costs (Basri, 2021; Chan et al., 2018a, b; Hansen \& Bøgh, 2021; Jablonska \& Polkowski, 2017; Ulas, 2019; Ulrich et al., 2021).

The COVID-19 pandemic has created risks for economies and business operations (OECD, 2020; Pardhan \& Drydakis, 2021), with customers stopping, reducing, or postponing purchases, thereby collapsing the supply chain, which has proved extremely difficult to source alternative suppliers (Bartika et al., 2020; Donthu \& Gustafsson, 2020; OECD, 2020; Papadopoulos et al., 2020). Given the unique characteristics of SMEs, e.g., resources constraints (Borch \& Madsen, 2007; Klein \& Todesco, 2021; Kreiser et al., 2013), it is unsurprising that approximately 80 per cent of the UK's SMEs have experienced a negative revenue impact and reduced cash flow during the COVID-19 pandemic (Bank of England, 2020; McKinsey \& Company, 2020). In 2020, a third of SMEs used AI applications such as chatbots and digital processing (Close Brothers Business Barometer, 2020). In 2021, 40 per cent of UK businesses, regardless of their size, planned to invest in AI to help them adapt to and recover from the COVID-19 pandemic (Fountech Solutions, 2021).

Limited research exists on the use of digital technology and $\mathrm{AI}$ for dealing with the business consequences of COVID-19 pandemic (Brem et al., 2021; Guo \& Polak, 
2021; Papadopoulos et al., 2020; Piccialli et al., 2021), therefore, this study aimed to evaluate whether AI applications can reduce SMEs' business risks caused by the COVID-19 pandemic in London, England. The study utilised the International Labor Organization's (ILO) SMEs COVID-19 pandemic business risks scale that measures business risks to people, processes, profits, and partnerships. Data were collected from 317 SMEs between April and June 2020 (wave one), with a follow-up survey conducted between October and December 2020 (wave two).

The theory of dynamic capabilities (Teece et al., 2016) provides a theoretical lens to approach the underlying mechanisms of the study objective. The development and exercise of dynamic capabilities are fundamental to business success (Teece, 2007). Dynamic capability is the grouping of organisational skills, processes and routines that differentiate companies in competitive markets (Teece, 2007) and is quantified through firms' R\&D expenditures, patterns, innovation processes and products (Laaksonen \& Peltoniemi, 2016). The present study evaluates that AI provides methods for SMEs to adapt to unprecedented conditions, meaning they leverage technology to meet new demands, move at speed to pivot their business operations, boost efficiency and reduce business risks (Garbellano \& Da Veiga, 2019; OECD, 2020; Sunday \& Vera, 2018). The AI applications enable SMEs to find new opportunities (sensing capabilities), exploit them (seizing capabilities) and change operational processes (transforming capabilities) (Day \& Schoemaker, 2016; Teece et al., 2016; Warner \& Wäger, 2019).

The present study reveals that AI applications are associated with reduced SMEs' business risks caused by the COVID-19 pandemic, that is, AI in SMEs can positively affect the performance of both small and medium enterprises. Moreover, AI applications to target consumers online, offer cash flow forecasting and facilitate HR activities are associated with reduced business risks caused by the COVID-19 pandemic. Reflecting on the theory of dynamic capabilities (Teece et al., 2016), AI can enable SMEs to enhance their capabilities. During the COVID-19 pandemic, $\mathrm{AI}$ in advertising could boost SMEs sensing capabilities through a more efficient prediction of market trends and facilitation of customers' needs. Moreover, $\mathrm{AI}$ in pricing and risk analysis could allow SMEs to seize capabilities through better-informed financial planning, with AI in HR increasing SMEs transformational capabilities through better-informed operational strategies.

The study indicates that AI, by enabling SMEs to enhance their dynamic capabilities, can increase their efficiency and reduce business risks associated with the COVID-19 pandemic. Given the theoretical considerations and estimated patterns of this study, it is proposed that AI enables SMEs to develop defence mechanisms and define solutions against adversities imposed by the COVID-19 pandemic. SMEs need to consider engaging with digital applications aided by $\mathrm{AI}$ if they are to be sustainable in challenging digital business environments, exploring and exploiting technologyenabled tools. Since the study found that AI is associated with reduced business risks in both small and medium firms, the recommendations of this study are relevant for managers regardless of SMEs' size.

The current study makes four contributions to the literature. First, a new quantitative scale that summarises the use of AI applications in SMEs was developed. The limited articles that examine AI into SMEs' operations were reviewed to develop a new 10-item scale to capture the use of AI applications in marketing and sales, virtual communication, predictions, pricing and cash flow, fake reviews, cybersecurity, recruitment, and legal services. A few studies have evaluated whether SMEs use applications aided by AI (Hansen \& Bøgh, 2021; Hercheui \& Ranjith, 2020; Kumar \& Kalse, 2021; Mendonça \& Andrade, 2018; Watney \& Auer, 2021), however, there is no systematic quantitative scale. OECD (2008) evaluated the importance of quantitative scales, indicating that quantitative scales can summarise patterns and assess and compare activity and progress in certain phenomena (OECD, 2008). In the present study, the proposed scale aims to give information systems scholars a quantitative assessment of the adoption of $\mathrm{AI}$ in SMEs. Firms' innovative practices cannot be purposefully developed or assessed if there is uncertainty regarding how they are manifest in the empirical world (Laaksonen \& Peltoniemi, 2016). Eisenhardt and Martin (2000) evaluated that dynamic capabilities should be measured through a binary variable, that is, a firm either has a best practice, process or routine, or not (Eisenhardt \& Martin, 2000; Laaksonen \& Peltoniemi, 2016). In the present study, the use of AI in SMEs is envisioned as a set of best practices related to digital transformation strategies that facilitate SMEs to enhance their performance.

Second, only a few studies have focused on SMEs and AI during the COVID-19 pandemic (ILO, 2020; Kumar \& Ayedee, 2021; Priyono et al., 2020) and the proposed scale enables to quantify whether the use of AI applications by SMEs as well as the number of AI applications in use by SMEs is associated with reduced business risks caused by the COVID-19 pandemic. This is the first known quantitative assessment capturing relevant associations that could provide useful insights in the research area. For instance, given SMEs resources constraints (Klein \& Todesco, 2021; Kreiser et al., 2013), the quantitative orientation of the study determines whether the association between AI applications in use and reduced business risks caused by the COVID-19 pandemic holds true for both small and medium enterprises, thereby enabling such enterprises to better assess whether AI can support their operations during periods of economic uncertainty. Currently, a corresponding evaluation scale is 
missing in the information systems literature focusing on SMEs and AI.

Third, the orientation of this study enables to approach the relationship between $\mathrm{AI}$ in SMEs and reduced business risks caused by the COVID-19 pandemic through the lens of dynamic capabilities theory (Teece, 2007). Measuring whether SMEs utilise AI determines whether they engage with the trend toward digitalisation and advanced technology (Warner \& Wäger, 2019), with the dynamic capabilities theory providing a comprehensive framework to examine the payoffs of the firms' digital transformation (Warner \& Wäger, 2019). Whether AI enables SMEs to enhance sensing, seizing and transforming capabilities and obtain business advantages during the COVID-19 pandemic has not been evaluated (Hercheui \& Ranjith, 2020; Mendonça \& Andrade, 2018), hence, given the increasing adoption of AI in entrepreneurship (Hansen \& Bøgh, 2021; Ulas, 2019) and the effects of COVID-19 pandemic (OECD, 2020), the present study evaluates what types of AI applications could enhance dynamic capabilities and increase SMEs performance during the COVID-19 pandemic. Such theoretical insights may be of interest to information systems scholars working on AI, dynamic capabilities and SMEs performance.

Fourth, the longitudinal study design captures the reverse causality and offers better-informed estimates (Morgan, 2013; Andreß et al., 2013; Menard, 2008). The present study, by utilising panel data, captures fluctuations in SMEs' responses to business risks caused by the COVID-19 pandemic and controls for potential reverse causality, such as from better financial performance and a higher level of innovativeness to higher adoption of AI. Endogeneity is a critical issue and efforts are needed to reduce spurious relationships (Laaksonen \& Peltoniemi, 2016), thus the use of longitudinal data in the present study provides more accurate estimates (Laaksonen \& Peltoniemi, 2016).

The rest of the article is organised as follows: Section 2 presents a review of the AI applications in business, Section 3 offers theoretical considerations, Section 4 discusses the data collection and variables, Section 5 presents the descriptive statistics, Section 6 describes the empirical framework, Section 7 presents the regression estimates and Section 8 is the discussion, with the conclusions provided in Section 9.

\section{Applications of Artificial Intelligence in Business}

AI affects a diverse range of industries from health care to retail (Campbell et al., 2020; Jablonska \& Polkowski, 2017) and allows systems to support human capabilities and intelligence by comprehending, acting, and learning (Drydakis,
2021; Enholm et al., 2021; Lichtenthaler, 2019; OECD, 2017; Shabbir \& Anwer, 2015). Moreover, AI advances big data collection and processing, analysis, drives conclusions and provides recommendations (Drydakis, 2021; Jablonska \& Polkowski, 2017; Bengio et al., 2013).

AI is utilised by SMEs to support their business operations in areas such as sales and marketing, conversational commerce, customer service support, data analytics, sustainable development, credit evaluations, risk assessments, cybersecurity and legal services (Basri, 2021; CamachoMiñano et al., 2015; Hamal \& Senvar, 2021; Ikumoro \& Jawad, 2019; Kim et al., 2019; Pérez et al., 2019; Rebón et al., 2015; Sood, 2020; Watney \& Auer, 2021), helping to improve the quality optimisation, operational efficiencies and overall development of SMEs (Hansen \& Bøgh, 2021; Kumar \& Kalse, 2021).

This section presents the incorporation of AI into business operations and reviews the limited number of studies that capture SMEs' realities, focussing on marketing systems, virtual communication, pricing and cash predictions, online reviews, cybersecurity, recruitment, and legal services. The section provides insights on the items that formed the study's scale of AI applications in use and informed the theoretical predictions.

\subsection{Marketing and sales}

The Internet and smartphones have increased the amount of information generated by customers to feed AI systems (Fan et al., 2020). Marketing automatisation systems and e-commerce implement AI-based techniques to improve customer targeting based on their habits, social media activities and profiles, online activities, and past transactions to develop more efficient interactions (Campbell et al., 2020; Jablonska \& Polkowski, 2017; Surendiran et al., 2010). Customer targeting is primarily disseminated among algorithms aimed at increasing conversion rates (Jablonska \& Polkowski, 2017; Surendiran et al., 2010), with firms using social sentiment analysis and natural language processing to analyse social media activity and other online content to identify customer needs (Fan et al., 2020; Davenport et al., 2020; Davidsson et al., 2018; Gaspar et al., 2016). The main goal is to deliver selected content to potential customers that will increase the chance of purchase (Jablonska \& Polkowski, 2017; Rekha et al., 2016).

AI customises firms' website content to match customers' preferences, offer prices to align with customers' willingness to pay and connect the customer interactions across all channels and devices in a seamless and personalised manner (Kumar et al., 2019). Such strategies help firms improve customer retention because of the preventive maintenance services based on AI algorithm predictions (Kumar et al., 2019). In addition, digital advertising services aided with AI 
enable firms to anticipate customers' needs and recommend specific offers $(\mathrm{Li}, 2019)$ in real-time by analysing large volumes of multisensory data accumulated on multiple touchpoints (Kietzmann et al., 2018; Wang et al., 2019). These data enable firms to gain insight into customer behavioural patterns, creating personalised advertisements and advertising impact evaluation (Li, 2019; Qin \& Jiang, 2019). AI leads to higher conversion rates, advanced customer services, increased customer experience, satisfaction, purchases and operational efficiency (Davenport et al., 2020; Jablonska \& Polkowski, 2017; Köse, 2017), helping SMEs in marketing and sales platforms to increase the number of customers and profitability (Basri, 2021).

\subsection{Chatbots}

Firms use chatbots to improve communication with customers (Jablonska \& Polkowski, 2017). Chatbots are programmes that facilitate interaction between humans and machines by using machines with natural-sounding voices that respond to natural language text and/or to voice inputs in a human-like manner (Lokman \& Zain, 2010). They provide personalised services to customers in the form of intelligent human conversation (Ikumoro \& Jawad, 2019), offering an efficient layer of support to service quality by assuring that a specific service is available to meet customer needs anytime and anywhere (Ikumoro \& Jawad, 2019). Chatbots enable firms to turn data into individual recommendations and large segment data to better understand their customers to develop a personal connection (Anshari et al., 2019; Chung et al., 2018). Firms using chatbots present their customers with highly targeted suggestions saving time and effort, thereby boosting customer loyalty (Anshari et al., 2019; Chung et al., 2018). Moreover, chatbots added with AI enhance timely query management and disbursal without any time constraints and waiting, enabling customers to communicate smoothly with firms (Jablonska \& Polkowski, 2017; Um et al., 2020; Vishnoi et al., 2018). Therefore, AI facilitates virtual communication to improve sales, customer services and satisfaction (Pérez et al., 2019).

\subsection{Predictions, pricing, and cash flow}

AI-enabled pricing algorithms facilitate personalised pricing by firms (Gautier et al., 2020; Woodcock, 2019). AI determines correlations between price and sales to monitor price changes, enable dynamic real-time pricing, and demand response optimisation (Jablonska \& Polkowski, 2017). Moreover, AI can detect pricing anomalies, such as pricing errors and nonprofitable customers (Campbell et al., 2020), allowing identifying changes in competitor behaviour and make rapid price changes to adapt to the environment (Campbell et al., 2020; Ezrachi \& Stucke, 2016).

Neural networks aided by AI help firms learn from incoming data and adjust their forecasts based on ongoing understanding, resulting in enhanced accuracy of earnings predictions and observed changes in earnings (Fiserv, 2017; Xinyue et al., 2020). These strategies aim to maximise cash flow by making advance fund predictions, preventing liquidity risks, minimising insurance risk, detecting anomalies in financial data, and adjusting investment strategies (Dadteev et al., 2020; Yang et al., 2019). AI has enabled firms to adopt risk control applications regarding cash flow (Yan \& Ouyang, 2018; Yang et al., 2018), helping SMEs in data analytics to recognise and analyse risks controls, offer credit evaluations, and risk strategies (Sood, 2020). In addition, $\mathrm{AI}$ enables SMEs in risk management to predict insolvency (Camacho-Miñano et al., 2015).

\subsection{Fake reviews}

Online reviews represent a critical and unavoidable facet of e-commerce (Wu et al., 2020) as they critically impact customers' purchase decisions (Wu et al., 2020). The growth of e-commerce is associated with the prevalence of fake online reviews ( $\mathrm{Li}, \mathrm{Du}$, et al., 2018; Li, Su, et al., 2018; Salehi-Esfahani \& Ozturk, 2018; Zhuang et al., 2018). Fake reviews increase uncertainty, mislead customers, damage the business's reputation, and weaken customers' purchase intentions (Wu et al., 2020). AI detection methods aim to identify fake reviews (Wu et al., 2020) by reviewing spam, spammer, and spammer group (Keshavarz et al., 2018; Wang et al., 2016). Opinion mining, nearest-neighbour algorithms, ensembles of classifiers and multi-layer perceptrons, and sentiment analysis prove vital for detecting fake reviews (Jiang et al., 2016; Kumaravel \& Bizu, 2019).

\subsection{Cybersecurity}

Cybersecurity is an emerging challenge for information technology management in business and society (Hatfield, 2018; Mrabet et al., 2018). AI helps by monitoring normal and abnormal activity and improving security performance and overall protection from an increasing number of sophisticated cyber threats (Chan, Morgan, et al., 2018; Chan, Teoh, et al., 2018). In addition, AI in cybersecurity can detect different cyber threats, such as denial of service attacks, remote to local attacks, user to root attacks, and probing and make real-time decisions (Chan et al., 2018; Chan, Morgan, et al., 2018). Furthermore, AI supports SMEs in cybersecurity to deal with complex cyber-attacks (Dörpinghaus, 2019; Kim et al, 2019), enabling SMEs to detect financial accounting 
fraud (Hamal \& Senvar, 2021) and detect fraud with credit card electronic transactions (Rebón et al., 2015).

\subsection{Recruitment and HR}

For many SMEs, attracting, selecting, and retaining skilled employees represents an integral strategic concern (Black \& van Esch, 2020; Hamilton \& Davison, 2018). AI in recruiting can perform tasks such as identifying, attracting, screening, assessing, interviewing and coordinating with job candidates (Black \& van Esch, 2020; Hamilton \& Davison, 2018), as AI can process information and make decisions at volumes and speeds that far exceed human capacity, resulting in operational effectiveness and cost reduction (Black \& van Esch, 2020). Indeed, AI-enabled recruiting systems prove less biased and more objective than humans (van Esch et al., 2014). AI tools can remove previous gender bias wording providing an equal number of male and female candidates (Black \& van Esch, 2020).

\subsection{Legal services}

$\mathrm{AI}$ in legal services is used in contract analytics, litigation, legal research, and mergers and acquisitions due diligence (Armour \& Sako, 2020), with AI-based tools such as natural language processing used in contract review and prediction (Alarie et al., 2018). AI increases productivity and efficiency, reducing the time taken to perform previously labour-intensive activities (Alarie et al., 2018; Armour \& Sako, 2020). Moreover, AI allows for greater openness, transparency, and personalisation of services (Greenleaf et al., 2018; Rostain, 2017). It has been suggested that AI applications meet client needs for lower-cost legal services of predictable quality (Armour \& Sako, 2020), providing law firms with tools that facilitate their financially viable transformation in the process of value creation (Alarie et al., 2018). Regarding SMEs, AI assists SMEs in legal services to use smart contract templates, receive instant contract analysis to ensure they receive fair terms, and automate certain aspects of compliance with laws like the General Data Protection Regulation (Watney \& Auer, 2021).

\section{Theoretical framework}

\subsection{Al and dynamic capabilities}

Based on the dynamic capabilities theory, firms adjust their resources to gain and sustain competitive advantages in a constantly changing context (Teece, 2018; Teece et al., 2016). Dynamic capabilities prove critical for firms' performance when they compete in environments where technological changes are systematic and new products and services require development to meet market changes (Hercheui \& Ranjith, 2020; Mendonça \& Andrade, 2018; Pisano \& Teece, 2007; Warner \& Wäger, 2019). SMEs are often short of most resources, including capital, with limited opportunities to directly influence the market structure and are incapable of competing with larger firms on the same terms concerning both size and resources (Borch \& Madsen, 2007; Klein \& Todesco, 2021; Kreiser et al., 2013). The aforementioned budget constraints require coping strategies to develop resources for innovative projects (Borch \& Madsen, 2007). SMEs have invested in an increasing number of activities to develop and explore the potential of digital innovation, new software solutions, and/or advances in data science (Kumar \& Kalse, 2021; Priyono et al., 2020; Sunday \& Vera, 2018; Wang \& Shi, 2011).

Digital and information technology transformation aided by AI can contribute to SMEs' dynamic capabilities for gaining competitive advantage and performance (Garbellano \& Da Veiga, 2019; Hercheui \& Ranjith, 2020; Priyono et al., 2020; Sunday \& Vera, 2018; Wang \& Shi, 2011). The development of dynamic capabilities relies on sensing, seizing, and transforming (Helfat \& Peteraf, 2015; Teece et al., 2016). Sensing capabilities focus on finding opportunities while seizing capabilities aims to exploit them (Teece et al., 2016) and transforming capabilities change operational processes (Teece et al., 2016).

Sensing describes the assessment of opportunities and needs existing outside of the firm, with AI helping SMEs to sense as it can identify opportunities such as finding and engaging with the right customers, improving customer retention, experience and purchases, offer personalised services and 24/7 communication (Basri, 2021; Hansen \& Bøgh, 2021; Kumar \& Kalse, 2021; Li, Du, et al., 2018; Li, Su, et al., 2018; Pérez et al., 2019).

Seizing refers to a firm's reaction to market needs to increase profitability, financial performance, turnover and market share (Teece et al., 2016). AI can enable SMEs to seize as it can initiate routines to offer dynamic real-time pricing, predict cash flow, fund and liquidity risks, and observe and predict competitors' behaviour and strategies (Basri, 2021; Hamal \& Senvar, 2021; Kumar \& Kalse, 2021; Rebón et al., 2015; Sood, 2020). Seizing implies making more effective decisions to deliver better processes and business models to achieve competitive advantages (Mendonça \& Andrade, 2018; Teece, 2007).

Moreover, transforming refers to renewing firm processes and maintaining their relevance (Teece, 2018). The framework indicates that transforming is integral to creating sustainable growth (Zahra et al., 2006) and requires that SMEs proactively work to streamline, adapt, and improve organisational practices (Teece et al., 2016). AI can enable SMEs to transform by the adoption and development of innovative technologies and operational systems (Hansen \& Bøgh, 
2021; Kumar \& Kalse, 2021; Watney \& Auer, 2021), reducing critical attacks that harm SMEs' operations and reputation by boosting cybersecurity (Dörpinghaus, 2019; Kim et al, 2019). In addition, AI in recruiting and legal services could boost outcomes relating to human capital and efficiency maximisation, as well as reducing the costs associated with time and resources (Kumar \& Kalse, 2021; Watney \& Auer, 2021).

Given the presented features, the current study indicates that AI can enable SMEs to sense, seize and transform, suggesting that AI enables SMEs to create, extend, and/or modify their capabilities and build strategic assets helping them to modify competitive positions (Day \& Schoemaker, 2016; Teece et al., 2016; Warner \& Wäger, 2019).

\subsection{Hypothesis building; COVID-19 pandemic, AI and dynamic capabilities}

During global health crises, such as the COVID-19 pandemic, the business landscape can change rapidly (Chamola et al., 2020; International Monetary Fund, 2020). Indeed, the COVID-19 pandemic has been associated with reduced sales and revenues resulting from lockdowns to save lives and/or cuts in households' income (Juergensen et al., 2020; Klein \& Todesco, 2021; Pedauga et al., 2022). A high level of digitisation remains crucial to keep the economy running during health crisis (Chamola et al., 2020; Teodorescu, 2014). Findings suggest that digital technology mitigated the SARS pandemic's economic disruption in 2003 (Katz et al., 2020). Technology, in particular, information technologies, can improve resilience, manage information, and support decision-making during periods of uncertainty (Chamola et al., 2020; Katz et al., 2020; Teodorescu, 2014).

During the COVID-19 pandemic, SMEs with a high level of digital maturity responded to the challenges by accelerating the transition toward digitalised firms (Priyono et al., 2020). This strategy was utilised by SMEs to support Industry 4.0 by developing or extending dynamic capabilities to remain competitive (Kumar \& Ayedee, 2021). SMEs reported increasing digital activity, including online interactions with their clients, online sales, and applications to conduct/collect payments (Klein \& Todesco, 2021). The theory of dynamic capabilities (Teece et al., 2016) provides a framework to approach the impact of AI on the way SMEs use their resources to deal with the COVID-19 pandemic's business challenges. The COVID-19 pandemic shifted the focus of SMEs and consumers to a virtual world, resulting in an increased online presence (Klein \& Todesco, 2021). AI can prove useful to evaluate consumers' needs, offer personalised suggestions and pricing, target customers, and predict market trends and competitors' behaviour (Basri, 2021; Kumar et al., 2019; Paschen et al., 2020; Pérez et al., 2019). The present study suggests that during the COVID-19 pandemic, AI applications can boost SMEs' sensing capabilities through a more efficient prediction of market trends and facilitation of customers' needs.

During the COVID-19 pandemic, predictive intelligence was helpful since firms could carry out more informed decision forecasting regarding cash flow and pricing (Campbell et al., 2020; Gautier et al., 2020). During challenging periods, AI enables SMEs to navigate complex risks scenarios, allow financial planners to observe demand and supply patterns and optimise cost through predictive maintenance, as well as to detect and account for behaviour changes and predict the effects of policies (Akpan et al., 2020; CamachoMiñano et al., 2015; Campbell et al., 2020; Sood, 2020). The current study indicates that during the COVID-19 pandemic, AI applications can enhance SMEs' seizing capabilities through better-informed financial risk planning.

Additionally, given the increased online presence, fraud detection applications reduced SMEs reputational and operational risks (Dörpinghaus, 2019; Kim et al, 2019; Kumaravel \& Bizu, 2019; Wu et al., 2020). Moreover the COVID19 pandemic forced SMEs to operate remotely (Klein \& Todesco, 2021). During periods of economic instability, AI can enable cognitive assistants to conduct structured work and allow team members to focus on value-adding activities resulting in cost reduction and increased effectiveness (Armour \& Sako, 2020; Black \& van Esch, 2020; Watney $\&$ Auer, 2021). The present study indicates that during the COVID-19 pandemic, AI applications can enhance SMEs' transforming capabilities through better-informed operational risks strategies and cost reduction strategies.

AI provides critical methods for SMEs to adapt to unprecedented conditions, meaning they leverage technology to meet new types of demand, move at speed to pivot their business operations, reduce risks and boost efficiency (Garbellano \& Da Veiga, 2019; OECD, 2020; Sunday \& Vera, 2018).

Consistent with existing theoretical and empirical evaluations, it is hypothesised that Artificial Intelligence applications can reduce SMEs' business risks caused by the COVID-19 pandemic.

Figure 1 presents the conceptual model entitled: AI Apps Business Payoffs.

\section{Data collection and variables}

The present study was designed as a longitudinal study intended to capture unobserved heterogeneity and reverse causality, offering better-informed estimates (Laaksonen \& Peltoniemi, 2016; Morgan, 2013). During the first lockdown in England (March-July 2020), electronic surveys were distributed to SMEs operating in London to collect data between April and June 2020. SMEs were identified through commercial lists of organisations in the UK and 


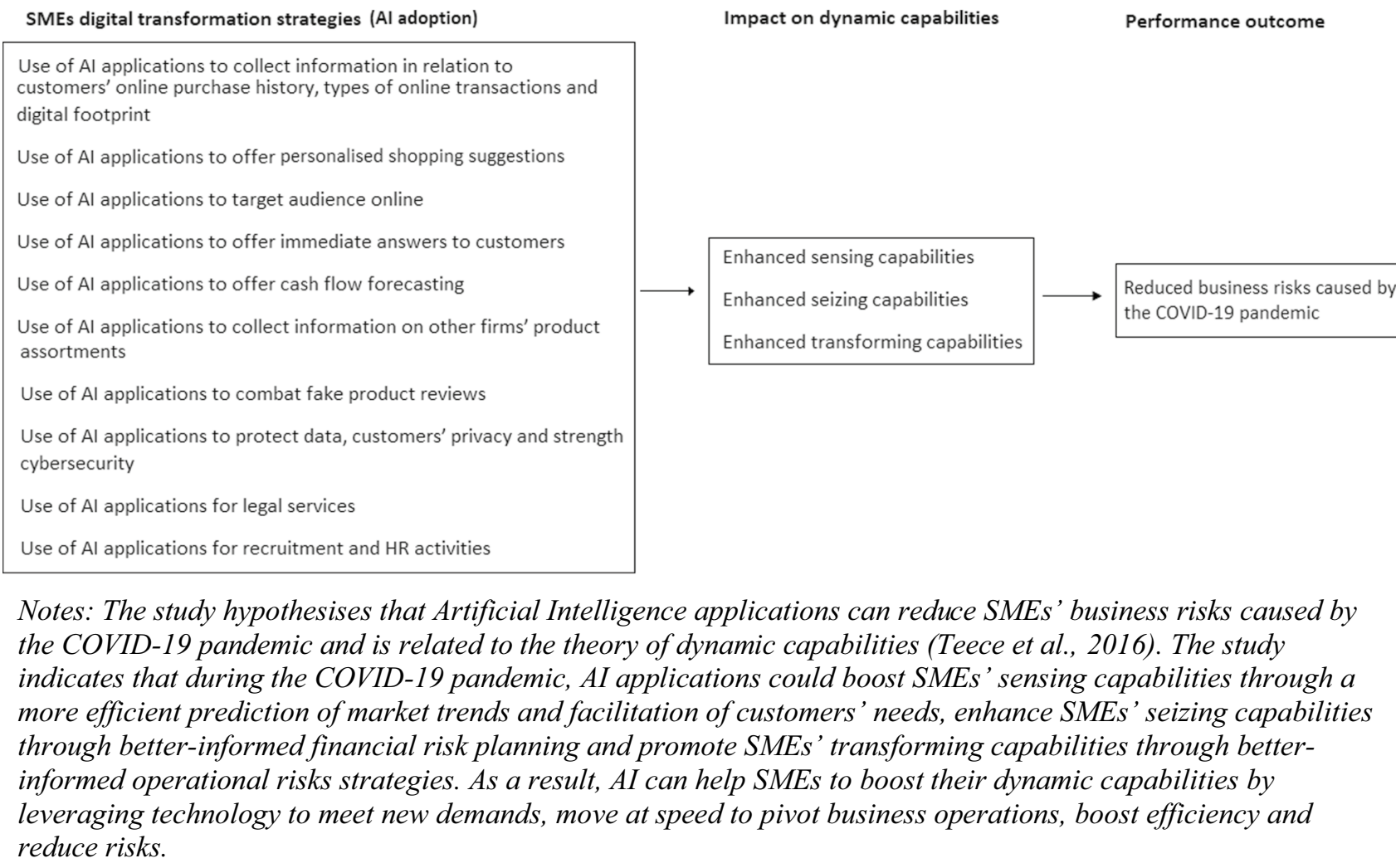

Fig. 1 Conceptual framework: AI Apps Business Payoffs. AI in SMEs and reduced business risks caused by the COVID-19 pandemic

the surveys were randomly forwarded to twelve industries, including the wholesale and retail trade, finance and insurance, and administration (see Table 1). A follow-up survey took place between October and December 2020 during the second lockdown in England (October-December 2020).

The surveys included questions on SMEs' turnover, gross asset, years of operation, business risks caused by the COVID19 pandemic, innovativeness, and AI applications in use and consisted of different sections, i.e., sub-questionnaires. Certain sections required filling out by information and technology personnel, while other sections were to be completed by finance personnel and/or general managers/directors. The opening letter invited contacts to forward the survey to relevant departments and/or personnel. The longitudinal nature of the survey was explained in the participation information sheets and each questionnaire indicated that participants had to provide their official emails and duties in the firm for follow-up contact. The participation information sheets indicated that the data would be pooled, thereby securing anonymity. The study followed the usual procedures for securing ethics approval and ensuring the anonymity of the participants.

The International Labor Organisation SMEs COVID-19 pandemic business risks scale (ILO, 2020) was utilised to measure business risks caused by the COVID-19 pandemic. This scale comprises 60 items to measure SMEs' risk profile or the level of vulnerability caused by the COVID-19 pandemic and its impact on four business thematic areas: risk to profits (16 items); risk to processes (eight items); risk to partnerships (17 items); and risk to people (19 items). The scale covers key corporate challenges such as reduced economic activity, declined productivity and motivation, accessing and securing production inputs, setting up contingency plans in cases of crises, and working from home.

A new 10-item scale measured the use of computer programmes aided by AI and/or digital applications aided by AI. Table 2 presents the ten applications in use. The questions/items were included after observing the patterns presented in the literature review section (Section 2) and each question measured whether SMEs have embodied AI in their operations. Eisenhardt and Martin (2000) indicated that dynamic capabilities could be empirically measured through a binary variable, i.e., whether a firm has a best practice, process or routine, constituting a dynamic capability or it does not (Laaksonen \& Peltoniemi, 2016). Such an approach enables researchers to build a dynamic capability 'profile' for each firm that could then be used as a basis for comparisons (Eisenhardt \& Martin, 2000; Laaksonen \& Peltoniemi, 2016). In the present study, the AI scale creates two variables. The first variable entitled 'Use of Artificial Intelligence Applications' represents a dichotomous variable 
Table 1 Descriptive statistics. SMEs characteristics

\begin{tabular}{|c|c|c|c|}
\hline & Panel I & Panel II & Panel III \\
\hline & $\begin{array}{l}\text { Period } \\
\text { April-June } 2020\end{array}$ & $\begin{array}{l}\text { Period } \\
\text { October-December } 2020\end{array}$ & Total sample \\
\hline Years of operation (c.) & $10.82(7.32)$ & $11.03(7.17)$ & $10.92(7.24)$ \\
\hline Medium enterprises (per cent $)^{\wedge}$ & $37.22(0.48)$ & $37.09(0.48)$ & $37.16(0.48)$ \\
\hline Turnover (per cent) $)^{\wedge \wedge}$ & $43.53(0.49)$ & $42.90(0.49)$ & $43.24(0.49)$ \\
\hline Gross assets (per cent)^^^ & $41.95(0.49)$ & $43.27(0.49)$ & $42.56(0.49)$ \\
\hline Manufacturing (per cent) & $4.73(0.21)$ & $4.36(0.20)$ & $4.56(0.20)$ \\
\hline Construction (per cent) & $4.10(0.19)$ & $4.00(0.19)$ & $4.05(0.19)$ \\
\hline Wholesale and retail trade (per cent) & $8.83(0.28)$ & $9.45(0.29)$ & $9.12(0.28)$ \\
\hline Financial and insurance (per cent) & $14.82(0.35)$ & $14.90(0.35)$ & $14.86(0.35)$ \\
\hline Information and communication (per cent) & $12.93(0.33)$ & $13.09(0.37)$ & $13.00(0.33)$ \\
\hline Transportation and storage (per cent) & $7.88(0.26)$ & $7.27(0.26)$ & $7.60(0.26)$ \\
\hline Real estate (per cent) & $8.51(0.27)$ & $8.00(0.27)$ & $8.27(0.27)$ \\
\hline Professional, scientific and technical services (per cent) & $9.46(0.29)$ & $10.18(0.30)$ & $9.79(0.29)$ \\
\hline Administrative and support services (per cent) & $9.77(0.29)$ & $10.18(0.30)$ & $9.96(0.29)$ \\
\hline Education (per cent) & $7.57(0.26)$ & $7.27(26.01)$ & $7.43(0.26)$ \\
\hline Health and social work services (per cent) & $5.67(0.23)$ & $6.18(0.24)$ & $5.91(0.23)$ \\
\hline Leisure, hospitality and tourism (per cent) & $5.67(0.23)$ & $5.09(0.22)$ & $5.40(0.22)$ \\
\hline SMEs business risks caused by the COVID-19 pandemic scale (c.) & $30.85(9.65)$ & $29.25(8.94)$ & $30.11(9.35)$ \\
\hline -Risks to people (c.) & $9.34(3.48)$ & $8.91(3.36)$ & $9.14(3.43)$ \\
\hline -Risks to processes (c.) & $3.93(1.70)$ & $3.84(1.53)$ & $3.89(1.62)$ \\
\hline -Risks to profits (c.) & $8.18(3.15)$ & $7.80(2.96)$ & $8.00(3.07)$ \\
\hline -Risks to partnerships (c.) & $9.38(3.10)$ & $8.69(2.93)$ & $9.06(3.04)$ \\
\hline Innovativeness scale (c.) & $79.96(41.57)$ & $80.11(39.37)$ & $80.03(40.53)$ \\
\hline -Propensity to create new products (c.) & $16.38(8.58)$ & $16.77(8.39)$ & $16.56(8.48)$ \\
\hline -Propensity to create new manufacturing processes (c.) & $15.86(8.32)$ & $16.02(8.08)$ & $15.93(8.20)$ \\
\hline -Propensity to create new business systems (c.) & $15.74(8.51)$ & $15.72(7.92)$ & $15.73(8.23)$ \\
\hline -Propensity to adopt new manufacturing processes (c.) & $16.10(8.37)$ & $15.86(7.94)$ & $15.99(8.17)$ \\
\hline -Propensity to adopt new business systems (c.) & $15.86(8.31)$ & $15.72(7.91)$ & $15.80(8.12)$ \\
\hline Observations (n) & 317 & 275 & 592 \\
\hline
\end{tabular}

(c.) Continuous variable. $\left({ }^{\wedge}\right)$ The reference category is small enterprises i.e., less than 50 employees. Medium enterprises consist of 50 to 250 employees. $\left({ }^{\wedge}\right)$ More than 10 million (reference less than 10 million). $\left(^{\wedge \wedge}\right)$ More than 5 million (reference less than 5 million). Standard deviations are in parenthesis

measuring whether, on average, an SME uses or does not use applications aided by AI. The second variable entitled 'Number of Artificial Intelligence applications in Use' is a continuous variable measuring how many applications aided by AI an SME uses. The variable ranges between 0 and 10 , with the more applications in use, the higher the value of the variable. The study reports descriptive statistics and estimates on both variables. ${ }^{1}$ By quantifying whether SMEs

\footnotetext{
1 The construction of the SMEs' AI applications in use scale adhered to the guidelines of DeVellis (2003) and Netermeyer et al. (2003) which propose a multilevel approach that includes (i) determination of what it is aimed to be measured, (ii) generation of an item pool, (iii) determination of the format for measurement, (iv) review of the questions by experts and (v) evaluation of the items and scale.
}

adopt AI, both variables capture whether SMEs strategically work to engage with the trend toward advanced technology and digital applications which could enhance their business capabilities and performance.

The 25-item scale of Knowles et al. (2008) was used to measure the innovation of SMEs. The scale covers five thematic areas, the propensity to create new products, generate new manufacturing processes, develop new business systems, adopt new manufacturing processes and business systems. The scale captures whether firms actively develop new products, compete with rival firms in the marketplace, and generate and implement in-house solutions to improve operations. Each thematic features five items and Appendix 1 provides the items per scale. 
Table 2 Descriptive statistics. Artificial Intelligence applications in use by SMEs

\begin{tabular}{|c|c|c|c|}
\hline & Panel I & Panel II & Panel III \\
\hline & $\begin{array}{l}\text { Period } \\
\text { April-June } 2020\end{array}$ & $\begin{array}{l}\text { Period } \\
\text { October- } \\
\text { December } \\
2020\end{array}$ & Total sample \\
\hline Use of AI applications (per cent) & $38.48(0.48)$ & $47.27(0.50)$ & $42.56(0.49)$ \\
\hline Number of AI applications in use (c.) & $1.31(2.16)$ & $1.62(2.30)$ & $1.46(2.23)$ \\
\hline $\begin{array}{l}\text { Use of AI applications to collect information in relation to customers' online purchase history, } \\
\text { types of online transactions and digital footprint (per cent) }\end{array}$ & $23.34(0.42)$ & $27.63(0.44)$ & $25.33(0.43)$ \\
\hline Use of AI applications to offer personalised shopping suggestions (per cent) & $17.03(0.37)$ & $18.90(0.39)$ & $17.90(0.38)$ \\
\hline Use of AI applications to target audience online (per cent) & $22.08(0.41)$ & $30.54(0.46)$ & $26.01(0.43)$ \\
\hline Use of AI applications to offer immediate answers to customers (per cent) & $23.02(0.42)$ & $28.00(0.44)$ & $25.33(0.43)$ \\
\hline Use of AI applications to offer cash flow forecasting (per cent) & $7.25(0.25)$ & $11.27(0.31)$ & $9.12(0.28)$ \\
\hline Use of AI applications to collect information on other firms' product assortments (per cent) & $7.57(0.26)$ & $10.90(0.31)$ & $9.12(0.28)$ \\
\hline Use of AI applications to combat fake product reviews (per cent) & $5.67(0.23)$ & $5.81(0.23)$ & $5.74(0.23)$ \\
\hline Use of AI applications to protect data, customers' privacy and strength cybersecurity (per cent) & $11.04(0.31)$ & $14.18(0.34)$ & $12.50(0.33)$ \\
\hline Use of AI applications for legal services (per cent) & $10.41(0.30)$ & $12.36(0.32)$ & $11.31(0.31)$ \\
\hline Use of AI applications for recruitment and HR activities (per cent) & $4.41(0.20)$ & $6.90(0.25)$ & $5.57(0.22)$ \\
\hline Observations (n) & 317 & 275 & 592 \\
\hline
\end{tabular}

(c.) Continuous variable. Standard deviations are in parenthesis

Table 3 Descriptive statistics. Proportions of Artificial Intelligence applications in use by SMEs

\begin{tabular}{llll}
\hline & Panel I & Panel II & Panel III \\
& $\begin{array}{l}\text { Period } \\
\text { April-June 2020 }\end{array}$ & $\begin{array}{l}\text { Period } \\
\text { October-December } \\
2020\end{array}$ & $\begin{array}{l}\text { Period } \\
\text { Total sample }\end{array}$ \\
& & $52.72(0.03)$ & $57.43(0.02)$ \\
\hline None AI application (per cent) & $61.51(0.02)$ & $13.45(0.02)$ & $12.83(0.13)$ \\
One AI application (per cent) & $12.30(0.01)$ & $9.09(0.01)$ & $6.75(0.01)$ \\
Two AI applications (per cent) & $4.73(0.01)$ & $2.90(0.01)$ & $3.37(0.01)$ \\
Three AI applications (per cent) & $3.78(0.01)$ & $4.72(0.01)$ & $4.39(0.01)$ \\
Four AI applications (per cent) & $4.10(0.01)$ & $6.18(0.01)$ & $5.23(0.01)$ \\
Five AI applications (per cent) & $4.41(0.01)$ & $5.09(0.01)$ & $4.89(0.01)$ \\
Six AI applications (per cent) & $4.73(0.01)$ & $5.09(0.01)$ & $4.39(0.01)$ \\
Seven AI applications (per cent) & $3.78(0.01)$ & $0.36(0.01)$ & $0.33(0.02)$ \\
Eight AI applications (per cent) & $0.31(0.01)$ & $0.36(0.01)$ & $0.33(0.01)$ \\
Nine AI applications (per cent) & $0.31(0.01)$ & 0 & 0 \\
Ten AI applications (per cent) & 0 & 275 & 592 \\
Observations (n) & 317 & &
\end{tabular}

Standard errors are in parenthesis

\section{Descriptive statistics}

Table 1 provides the descriptive statistics of the study, with panel I presenting the statistics for April-June 2020, panel II for October-December 2020 and the pooled data in panel III showing that $37.1 \%$ of the firms are medium enterprises (i.e., between 50 and 250 employees). The SMEs have been operating for 10.9 years on average, with $43.2 \%$ having a turnover of more than 10 million and $42.5 \%$ having gross assets of more than 5 million. The findings show that $14.8 \%$ of the SMEs are in the financial and insurance industry, followed by the information and communication industry (13\%), administration (9.9\%), and professional, scientific, and technical activities (9.7\%).

Table 1 presents information on the International Labor Organizations' SMEs COVID-19 pandemic business risks scale (ILO, 2020), which is 30.8 in panel I and 29.2 in panel II. Information on risks to people, processes, profits, and partnerships are offered per period. Moreover, information 
Table 4 Alpha tests per scale

\begin{tabular}{lll}
\hline Panel I & Panel II & Panel III \\
\hline Artificial Intelligence & Firms & SMEs business risks \\
$\begin{array}{l}\text { applications in use by } \\
\text { SMEs }\end{array}$ & Innova- & caused by the COVID-19 \\
0.84 & 0.92 & 0.82 \\
\hline
\end{tabular}

Total sample $(n=592)$

on the innovativeness scale (Knowles et al., 2008) is presented, which is 79.9 in panel I and 80.1 in panel II.
Table 2 offers statistics on AI applications in use, with an average number of AI applications in use of 1.31 (out of 10 ) in panel 1 and 1.62 in panel II. Moreover, $38.4 \%$ of the SMEs in panel 1 have used AI applications and $47.2 \%$ of the SMEs in panel II have used AI applications. Information on each one of the ten applications is offered, showing that 26\% of the SMEs use advertising applications to target audience online, followed by $25.3 \%$ of SMEs using marketing applications to collect information in relation to customers' online purchase history, types of online transactions, and digital footprint, and $25.3 \%$ of the SMEs use chat applications to offer immediate answers to customers.

Table 5 Descriptive statistics. SMEs business risks caused by the COVID-19 pandemic and Artificial Intelligence applications in use

\begin{tabular}{|c|c|c|}
\hline & $\begin{array}{l}\text { SMEs business risks caused by the } \\
\text { COVID- } 19 \text { pandemic (c.) }\end{array}$ & $\begin{array}{l}\text { Number } \\
\text { of SMEs }\end{array}$ \\
\hline \multicolumn{3}{|c|}{ Use of AI applications } \\
\hline -Yes & $23.66(7.84)$ & 252 \\
\hline -No & $34.89(7.29)$ & 340 \\
\hline \multicolumn{3}{|c|}{ Use of AI applications to collect information in relation to customers' online purchase history, types of online transactions and digital footprint } \\
\hline -Yes & $22.26(7.82)$ & 150 \\
\hline$-\mathrm{No}$ & $32.77(8.28)$ & 442 \\
\hline \multicolumn{3}{|c|}{ Use of AI applications to offer personalised shopping suggestions } \\
\hline -Yes & $21.12(6.57)$ & 107 \\
\hline$-\mathrm{No}$ & $32.07(8.70)$ & 485 \\
\hline \multicolumn{3}{|c|}{ Use of AI applications to target audience online } \\
\hline -Yes & $22.46(7.67)$ & 153 \\
\hline -No & $32.79(8.36)$ & 439 \\
\hline \multicolumn{3}{|c|}{ Use of AI applications to offer immediate answers to customers } \\
\hline -Yes & $22.36(7.46)$ & 149 \\
\hline -No & $32.73(8.43)$ & 443 \\
\hline \multicolumn{3}{|c|}{ Use of AI applications to offer cash flow forecasting } \\
\hline -Yes & $20.61(7.48)$ & 54 \\
\hline$-\mathrm{No}$ & $31.06(8.99)$ & 538 \\
\hline \multicolumn{3}{|c|}{ Use of AI applications to collect information on other firms' product assortments } \\
\hline -Yes & $20.88(7.59)$ & 54 \\
\hline$-\mathrm{No}$ & $31.03(9.01)$ & 538 \\
\hline \multicolumn{3}{|c|}{ Use of AI applications to combat fake product reviews } \\
\hline -Yes & $17.97(4.92)$ & 40 \\
\hline$-\mathrm{No}$ & $30.85(9.05)$ & 552 \\
\hline \multicolumn{3}{|c|}{ Use of AI applications to protect data, customers' privacy and strength cybersecurity } \\
\hline -Yes & $21.27(8.16)$ & 74 \\
\hline$-\mathrm{No}$ & $31.37(8.82)$ & 518 \\
\hline \multicolumn{3}{|c|}{ Use of AI applications for legal services } \\
\hline -Yes & $20.58(7.26)$ & 67 \\
\hline$-\mathrm{No}$ & $31.32(8.88)$ & 525 \\
\hline \multicolumn{3}{|c|}{ Use of AI applications for recruitment and HR activities } \\
\hline -Yes & $21.48(7.40)$ & 33 \\
\hline$-\mathrm{No}$ & $30.62(9.21)$ & 559 \\
\hline
\end{tabular}

Total sample $(n=592)$. (c.) Continuous variable. Standard deviations are in parenthesis. The differences per category are statistically significant at the 1 per cent level 
Table 6 Descriptive statistics. Tabulation analysis

$\begin{array}{lll}\begin{array}{l}\text { SMEs business risks } \\ \text { caused by the COVID-19 }\end{array} & \begin{array}{l}\text { Use of Artificial Intelli- } \\ \text { gence applications }\end{array} & \begin{array}{l}\text { Number of Artificial } \\ \text { Intelligence applications }\end{array} \\ \text { (per cent) } & \text { in use }\end{array}$

(c.)

\begin{tabular}{|c|c|c|c|}
\hline \multicolumn{4}{|l|}{ Number of employees } \\
\hline $\begin{array}{l}\text {-Medium enterprises } \\
\text { (between } 50 \text { and } 250 \text { employees) } \\
\mathrm{n}=220\end{array}$ & $22.91(6.38)$ & $70.45(0.45)$ & $2.60(2.54)$ \\
\hline $\begin{array}{l}\text {-Small enterprises } \\
\text { (less than } 50 \text { employees) } \\
\mathrm{n}=372\end{array}$ & $34.36(8.15)$ & $26.07(0.43)$ & $0.78(1.70)$ \\
\hline \multicolumn{4}{|l|}{ Turnover } \\
\hline $\begin{array}{l}\text {-More than } 10 \text { million } \\
\mathrm{n}=256\end{array}$ & $23.54(6.88)$ & $67.18(0.47)$ & $2.47(2.54)$ \\
\hline $\begin{array}{l}\text {-Less than } 10 \text { million } \\
\mathrm{n}=336\end{array}$ & $35.11(7.77)$ & $23.80(0.42)$ & $0.68(1.58)$ \\
\hline \multicolumn{4}{|l|}{ Gross assets } \\
\hline $\begin{array}{l}\text {-More than } 5 \text { million } \\
\mathrm{n}=252\end{array}$ & $23.56(6.78)$ & $67.48(0.46)$ & $2.49(2.54)$ \\
\hline $\begin{array}{l}\text {-Less than } 5 \text { million } \\
\mathrm{n}=340\end{array}$ & $34.96(7.94)$ & $42.11(0.42)$ & $0.69(1.58)$ \\
\hline \multicolumn{4}{|l|}{ Years of operation } \\
\hline $\begin{array}{l}\text {-More than } 5 \text { years } \\
\mathrm{n}=466\end{array}$ & $28.17(9.01)$ & $49.14(0.50)$ & $1.75(2.37)$ \\
\hline $\begin{array}{l}\text {-Less than } 5 \text { years } \\
\mathrm{n}=126\end{array}$ & $37.28(6.76)$ & $18.25(0.38)$ & $0.35(0.99)$ \\
\hline \multicolumn{4}{|l|}{ Innovativeness } \\
\hline $\begin{array}{l}\text {-High innovativeness level [more than } 80 \text { units in } \\
\text { Knowles et al. (2008) scale] } \\
\mathrm{n}=287\end{array}$ & $22.98(6.44)$ & $66.55(0.47)$ & $2.44(2.51)$ \\
\hline $\begin{array}{l}\text {-Low innovativeness level } \\
\text { [less than } 80 \text { units in Knowles et al. (2008) scale] } \\
\mathrm{n}=305\end{array}$ & $36.81(6.17)$ & $20.00(0.40)$ & $0.53(1.40)$ \\
\hline
\end{tabular}

Total sample $(n=592)$. (c.) Continuous variable. Standard deviations are in parenthesis. The differences per category are statistically significant at the 1 per cent level

Table 3 offers the proportions of AI applications in use, with $12.8 \%$ of all SMEs using one AI application, $6.75 \%$ of the SMEs using two AI applications, and $5.2 \%$ of the SMEs using five AI applications.

Table 4 presents the Cronbach's alpha coefficients, with all scales surpassing the Cronbach's alpha threshold (0.7), therefore internal consistency exists in all cases (Cortina, 1993; McKelvie \& Davidsson, 2009).

Table 5 presents the descriptive statistics on SMEs' business risks caused by the COVID-19 pandemic (ILO, 2020), showing that SMEs using AI applications experience lower business risks caused by the COVID-19 pandemic (23.6 versus 34.8). SMEs using virtual assistants to offer personalised shopping suggestions experience business risks caused by the COVID-19 pandemic of 21.1, whereas those SMEs not using relevant applications experience business risks caused by the COVID-19 pandemic of 32 .

Table 6, presents that small enterprises experience higher business risks caused by the COVID-19 pandemic than medium enterprises (34.3 versus 22.9). Moreover, it is found that the percentage of small enterprises utilising AI applications is lower than that of medium enterprises $(26.0 \%$ versus $70.4 \%$ ). In addition, it is found that SMEs with lower turnover, gross assets, years of operation and innovativeness levels experience higher business risks caused by the COVID-19 pandemic than those of SMEs with higher turnover, gross assets, years of operation and innovativeness level.

Table 7 presents a correlation matrix for the total sample. A negative correlation exists between business risks caused by the COVID-19 pandemic and the use of AI applications, and the number of AI applications. The outcomes indicate that SMEs which use AI applications experience lower business risks caused by the COVID-19 pandemic. Moreover, the findings show that the use of AI applications is positively associated with enterprise size, turnover, gross assets, years of operation and innovativeness level. Furthermore, the findings show that business risks caused by the COVID-19 pandemic 
Table 7 Correlation matrix

\begin{tabular}{|c|c|c|c|c|c|c|c|c|}
\hline & $\begin{array}{l}\text { SMEs business } \\
\text { risks caused by } \\
\text { the COVID-19 } \\
\text { pandemic }\end{array}$ & $\begin{array}{l}\text { Use of Artificial } \\
\text { Intelligence } \\
\text { applications }\end{array}$ & $\begin{array}{l}\text { Number of } \\
\text { Artificial Intelli- } \\
\text { gence applica- } \\
\text { tions in use }\end{array}$ & Innovativeness & $\begin{array}{l}\text { Years of opera- } \\
\text { tion }\end{array}$ & $\begin{array}{l}\text { Medium } \\
\text { enterprises } \\
(\wedge)\end{array}$ & Turnover $(\wedge \wedge)$ & $\begin{array}{l}\text { Gross } \\
\text { assets } \\
(\wedge \wedge \wedge)\end{array}$ \\
\hline $\begin{array}{l}\text { SMEs busi- } \\
\text { ness risks } \\
\text { caused by the } \\
\text { COVID-19 } \\
\text { pandemic }\end{array}$ & 1 & & & & & & & \\
\hline $\begin{array}{l}\text { Use of Artificial } \\
\text { Intelligence } \\
\text { applications }\end{array}$ & $\begin{array}{l}-0.59 \\
(0.00)^{* * *}\end{array}$ & 1 & & & & & & \\
\hline $\begin{array}{l}\text { Number of } \\
\text { Artificial } \\
\text { Intelligence } \\
\text { applications } \\
\text { in use }\end{array}$ & $\begin{array}{l}-0.61 \\
(0.00)^{* * *}\end{array}$ & $\begin{array}{l}0.72 \\
(0.00)^{* * *}\end{array}$ & 1 & & & & & \\
\hline Innovativeness & $\begin{array}{l}-0.86 \\
(0.00)^{* * *}\end{array}$ & $\begin{array}{l}0.59 \\
(0.00)^{* * *}\end{array}$ & $\begin{array}{l}0.56 \\
(0.00)^{* * *}\end{array}$ & 1 & & & & \\
\hline $\begin{array}{l}\text { Years of opera- } \\
\text { tion }\end{array}$ & $\begin{array}{l}-0.51 \\
(0.00)^{* * *}\end{array}$ & $\begin{array}{l}0.37 \\
(0.00)^{* * *}\end{array}$ & $\begin{array}{l}0.32 \\
(0.00)^{* * *}\end{array}$ & $\begin{array}{l}0.59 \\
(0.00)^{* * *}\end{array}$ & 1 & & & \\
\hline $\begin{array}{l}\text { Medium enter- } \\
\text { prises }\left({ }^{\wedge}\right)\end{array}$ & $\begin{array}{l}-0.59 \\
(0.00)^{* * *}\end{array}$ & $\begin{array}{l}0.43 \\
(0.00)^{* * *}\end{array}$ & $\begin{array}{l}0.39 \\
(0.00)^{* * *}\end{array}$ & $\begin{array}{l}0.69 \\
(0.00)^{* * *}\end{array}$ & $\begin{array}{l}0.48 \\
(0.00) * * *\end{array}$ & 1 & & \\
\hline Turnover $(\wedge \wedge)$ & $\begin{array}{l}-0.61 \\
(0.00)^{* * *}\end{array}$ & $\begin{array}{l}0.43 \\
(0.00)^{* * *}\end{array}$ & $\begin{array}{l}0.39 \\
(0.00)^{* * *}\end{array}$ & $\begin{array}{l}0.71 \\
(0.00)^{* * *}\end{array}$ & $\begin{array}{l}0.47 \\
(0.00) * * *\end{array}$ & $\begin{array}{l}0.88 \\
(0.00)^{* * *}\end{array}$ & 1 & \\
\hline $\begin{array}{l}\text { Gross assets } \\
(\wedge \wedge \wedge)\end{array}$ & $\begin{array}{l}-0.60 \\
(0.00)^{* * *}\end{array}$ & $\begin{array}{l}0.43 \\
(0.00)^{* * *}\end{array}$ & $\begin{array}{l}0.39 \\
(0.00)^{* * *}\end{array}$ & $\begin{array}{l}0.70 \\
(0.00)^{* * *}\end{array}$ & $\begin{array}{l}0.45 \\
(0.00)^{* * *}\end{array}$ & $\begin{array}{l}0.89 \\
(0.00)^{* * *}\end{array}$ & $\begin{array}{l}0.93 \\
(0.00)^{* * *}\end{array}$ & 1 \\
\hline
\end{tabular}

Total sample $(n=592) .\left({ }^{\wedge}\right)$ The reference category is small enterprises, i.e., less than 50 employees. Medium enterprises consist of 50 to 250 employees. $\left({ }^{\wedge}\right)$ More than 10 million (reference less than 10 million). $\left(^{\wedge \wedge}\right)$ More than 5 million (reference less than 5 million). P-values are in parenthesis. (***) Statistically significant at the 1 per cent level

are negatively associated with enterprises size, turnover, gross assets, years of operation and innovativeness level.

\section{Data analysis}

Table 8 presents the random-effects models (Menard, 2008; Wooldridge, 2010), with Model I examining the association between the use of AI applications and SMEs' business risks caused by the COVID-19 pandemic. The specification includes information on years of operation, firm size, turnover, gross assets, innovativeness, and industries. Model II assesses the association between the number of AI applications in use and SMEs' business risks caused by the COVID-19 pandemic, replicating the empirical framework presented in Model I. The two models assess the study aim through two alternative variables, allowing observation of whether the patterns are robust across different specifications. If the AI estimates are statistically significant in Models I and II, where critical information is included, then the empirical specification is not sensitive due to unobserved factors related to the use of AI applications (Clarke, 2005). Table 9 assesses the ten AI applications in use and Table 10 decomposes the SMEs' business risks scale caused by the COVID-19 pandemic into four themes. Model I assesses business risks to people, Model II presents estimates on business risks to processes, Model III offers business risks to profits and Model IV presents business risks to partnerships.

Table 11 provides a further robustness analysis, evaluating the association between the use of AI applications and SMEs risks caused by the COVID-19 pandemic by splitting the sample by enterprise size (medium/small), turnover (more/less than 10 million), gross assets (more/less than 5 million), years of operation (more/less than 5 years), and innovativeness level (more/less than 80 units in Knowles et al. (2008) innovativeness scale).

The present study utilising panel data captures fluctuations in SMEs' responses to business risks caused by the COVID19 pandemic and controls for potential reverse causality, such as from better financial performance to higher adoption of AI applications. Moreover, since information on innovativeness is included in all models, it is feasible to control for relevant spurious relationships and unobserved heterogeneity since AI is one demonstration of innovativeness. Moreover, each model includes information for years of operations and financial performance. If the use of $\mathrm{AI}$ applications is 
Table 8 Estimates. SMEs business risks caused by the COVID-19 pandemic

\begin{tabular}{|c|c|c|}
\hline & Model I & Model II \\
\hline $\begin{array}{c}\text { Use of Artificial Intel- } \\
\text { ligence applications }\end{array}$ & $\begin{array}{l}-2.203 \\
(0.542)^{* * *}\end{array}$ & - \\
\hline $\begin{array}{l}\text { Number of Artificial } \\
\text { Intelligence applica- } \\
\text { tions in use }\end{array}$ & - & $\begin{array}{l}-0.801 \\
(0.144)^{* * *}\end{array}$ \\
\hline Innovativeness scale & $\begin{array}{l}-0.184 \\
(0.009)^{* * *}\end{array}$ & $\begin{array}{l}-0.177 \\
(0.009)^{* * *}\end{array}$ \\
\hline Years of operation & $\begin{array}{l}0.011 \\
(0.031)\end{array}$ & $\begin{array}{l}0.005 \\
(0.031)\end{array}$ \\
\hline Medium enterprises $^{\wedge}$ & $\begin{array}{l}0.245 \\
(0.955)\end{array}$ & $\begin{array}{l}0.241 \\
(0.880)\end{array}$ \\
\hline Turnover $^{\wedge \wedge}$ & $\begin{array}{l}0.222 \\
(0.977)\end{array}$ & $\begin{array}{l}0.160 \\
(0.927)\end{array}$ \\
\hline Gross assets ${ }^{\wedge \wedge \wedge}$ & $\begin{array}{l}-0.545 \\
(0.944)\end{array}$ & $\begin{array}{l}-0.351 \\
(0.856)\end{array}$ \\
\hline Wald test & $2237.57 ; p=0.000$ & $2318.10 ; p=0.000$ \\
\hline $\mathrm{R}^{2}$ & 0.767 & 0.779 \\
\hline Observations (n) & 592 & 592 \\
\hline
\end{tabular}

$\left(^{\wedge}\right)$ The reference category is small enterprises, i.e., less than 50 employees. Medium enterprises consist of 50 to 250 employees. $\left({ }^{\wedge}\right)$ More than 10 million (reference less than 10 million). ( $\left.{ }^{\wedge \wedge}\right)$ More than 5 million (reference less than 5 million). Each model incorporates information on industry heterogeneity. Robust standard errors are reported in parentheses. (***) Statistically significant at the 1 per cent

more prevalent in SMEs with more years of operation and in wealthier SMEs affecting the outcomes of interest, then the empirical specifications should capture these patterns.

The analysis indicates that firm performance is a key outcome of the dynamic capability theory and is usually seen as the ultimate aim of dynamic capabilities (Laaksonen \& Peltoniemi, 2016). Given the study design, the observable variables are the adoption of AI in SMEs as well as SMEs business risks caused by the COVID-19 pandemic. In the present setting, whether AI boosts SMEs' dynamic capacities is empirically indistinguishable from whether AI applications adoption can be perceived as the actual dynamic capabilities of the SMEs. Following Laaksonen and Peltoniemi (2016), dynamic capabilities were evaluated based on the achieved outputs (i.e., SMEs business risks caused by the COVID-19 pandemic), rather than only looking at investment levels or new products (i.e., adoption of AI applications in SMEs). Given the fact that this study does not have data on SMEs' operational and organisational routines, processes, and practices, it cannot measure mediation effects, so whether AI applications influence SMEs' performance through mediators (e.g., operational and organisational advantages) can only be approached theoretically not empirically. The present study assesses the combined effect of (i) AI adoption in SMEs and (ii) AI in SMEs' sensing, seizing and transforming capabilities on SMEs business risks caused by the COVID-19 pandemic.

\section{Regression outcomes}

\subsection{Main results}

In Table 8, Model I shows that the use of AI applications is associated with $3.1 \%^{2}$ lower business risks caused by the COVID-19 pandemic ( $\beta=-2.203, \mathrm{p}=0.00$ or $\varepsilon=-3.1 \%)$, hence the hypothesis is accepted, AI in SMEs is associated with reduced business risks caused by the COVID-19 pandemic. In addition, Model II indicates that the number of AI applications in use is associated with $3.8 \%$ lower business risks caused by the COVID-19 pandemic $(\beta=-0.801$, $\mathrm{p}=0.00$ or $\varepsilon=-3.8 \%)^{3}$

Table 9 offers insights into the ten AI applications in use, indicating a negative association between SMEs' business risks caused by the COVID-19 pandemic and use of advertising applications to target the audience online $(\beta=-1.958$, $\mathrm{p}=0.00$ or, $\varepsilon=-1.6 \%$ ), use of applications to offer cash flow forecasting $(\beta=-1.886, p=0.01$ or, $\varepsilon=-0.5 \%)$, and use of applications for recruitment and HR activities $(\beta=-1.335$, $\mathrm{p}=0.04$ or, $\varepsilon=-0.2 \%$ ).

Table 10 presents estimates on the SMEs' business risk items. Model I indicates a negative association between business risks to people caused by the COVID-19 pandemic and use of marketing applications to collect information in relation to customers' online purchase history, types of online transactions and digital footprint $(\beta=-0.690, p=0.02$ or $\varepsilon=-1.9 \%$ ), use of advertising applications to target audience online $(\beta=-0.944, p=0.00$ or $\varepsilon=-2.6 \%)$, and use of digital applications to offer cash flow forecasting $(\beta=-0.768$, $\mathrm{p}=0.04$ or $\varepsilon=-0.7 \%$ ). Moreover, Model III estimates a negative association between risks to profits caused by the COVID-19 pandemic and use of virtual assistants to offer personalised shopping suggestions $(\beta=-0.940, \mathrm{p}=0.00$ or $\varepsilon=-2.0 \%)$ and use of advertising applications to target audience online $(\beta=-0.375, p=0.03$ or $\varepsilon=-1.2 \%)$. Finally, Model IV estimates a negative association between risks to partnerships caused by the COVID-19 pandemic and the use

\footnotetext{
2 A one standard deviation increase in the use of AI applications is associated with a $3.1 \%$ decline in business risks caused by the COVID-19 pandemic (elasticity effect; $\varepsilon$ ).

${ }^{3}$ In Table 8, if observations from SMEs that only participated in the first survey but did not participate in the second survey are excluded from the analysis $(n=42)$, then comparable results are estimated. For instance, the use of AI applications $(\beta=-2.039, \mathrm{p}=0.00$ or $\varepsilon=-3.0 \%$, $\mathrm{n}=550)$ and the number of AI applications used $(\beta=-0.745, \mathrm{p}=0.00$ or $\varepsilon=-3.8 \%, \mathrm{n}=550$ ) are associated with less business risks caused by the COVID-19 pandemic.
} 
Table 9 Estimates. SMEs business risks caused by the COVID-19 pandemic

\begin{tabular}{ll}
\hline & Model I \\
\hline $\begin{array}{l}\text { Use of AI applications to collect information in relation to customers' online purchase } \\
\text { history, types of online transactions and digital footprint }\end{array}$ & $0.156(0.648)$ \\
Use of AI applications to offer personalised shopping suggestions & $-1.230(0.825)$ \\
Use of AI applications to target audience online & $-1.958(0.594)^{* * *}$ \\
Use of AI applications to offer immediate answers to customers & $-0.386(0.550)$ \\
Use of AI applications to offer cash flow forecasting & $-1.886(0.772)^{* *}$ \\
Use of AI applications to collect information on other firms' product assortments & $-0.503(0.713)$ \\
Use of AI applications to combat fake product reviews & $0.426(0.894)$ \\
Use of AI applications to protect data, customers' privacy and strength cybersecurity & $-0.283(0.793)$ \\
Use of AI applications for legal services & $-0.278(0.692)$ \\
Use of AI applications for recruitment and HR activities & $-1.355(0.688)^{* *}$ \\
Propensity to create new products & $-0.375(0.086)^{* * *}$ \\
Propensity to create new manufacturing processes & $-0.115(0.091)$ \\
Propensity to create new business systems & $-0.382(0.089)^{* * *}$ \\
Propensity to adopt new manufacturing processes & $-0.004(0.075)$ \\
Propensity to adopt new business systems & $-0.026(0.084)$ \\
Years of operation & $0.018(0.033)$ \\
Medium enterprises^ & $-0.050(0.841)$ \\
Turnover^^ & $0.068(0.957)$ \\
Gross assets^^^ & $0.112(0.874)$ \\
Wald test & $2674.57 ; \mathrm{p}=0.000$ \\
$\mathrm{R}^{2}$ & 0.786 \\
Observations (n) & 592 \\
\hline
\end{tabular}

$\left(^{\wedge}\right)$ The reference category is small enterprises, i.e., less than 50 employees. Medium enterprises consist of 50 to 250 employees. $\left({ }^{\wedge}\right)$ More than 10 million (reference less than 10 million). $\left({ }^{\wedge \wedge}\right)$ More than 5 million (reference less than 5 million). The model incorporates information on industry heterogeneity. Robust standard errors are reported in parentheses. (***) Statistically significant at the 1 per cent. (**) Statistically significant at the 5 per cent of applications for recruitment and HR purposes $(\beta=-1.017$, $\mathrm{p}=0.01$ or $\varepsilon=-0.6 \%)$.

Taken together, innovativeness is associated with a reduction in SMEs' business risks caused by the COVID19 pandemic.

\subsection{Robustness tests}

Table 11 offers the robustness tests, indicating a statistically significant negative association between the use of AI applications and business risks caused by the COVID-19 pandemic. Both small and medium enterprises, less wealthy and wealthier SMEs, younger and older SMEs, as well as less innovative and more innovative SMEs experience reduced business risks caused by the COVID-19 pandemic by using AI applications.

It was observed that medium enterprises, SMEs with higher turnover and gross assets, and SMEs with higher innovativeness level experience higher AI payoffs (in terms of reduced business risks) than small enterprises, SMEs with lower turnover and gross assets, and SMEs with lower innovativeness level. For instance, Model I estimates that the use of AI applications in medium enterprises is associated with $9.2 \%$ lower business risks caused by the COVID-19 pandemic $(\beta=-3.024, p=0.00$ or $\varepsilon=-9.2 \%)$, whereas Model II shows that the use of AI applications in small enterprises is associated with $1.3 \%$ lower business risks caused by the COVID-19 pandemic ( $\beta=-1.836, p=0.00$ or $\varepsilon=-1.3 \%)$. In both models, the estimates are statistically significant at the $1 \%$ level.

\section{Discussion}

\subsection{Outcome evaluations}

The outbreak and rapid spread of COVID-19 have disrupted lives, communities, and economies worldwide (Donthu \& Gustafsson, 2020). In the UK, the decline in GDP was approximately $9 \%$ in 2020 , the most substantial fall ever recorded (Office for National Statistics, 2020). The present study hypothesised that AI applications are associated with reduced business risks of SMEs in London, England. The theory of dynamic capabilities (Teece et al., 2016) provided 
Table 10 Estimates. SMEs business risks caused by the COVID-19 pandemic

\begin{tabular}{|c|c|c|c|c|}
\hline & $\begin{array}{l}\text { Model I } \\
\text { Risks to people }\end{array}$ & $\begin{array}{l}\text { Model II } \\
\text { Risks to processes }\end{array}$ & $\begin{array}{l}\text { Model III } \\
\text { Risks to profits }\end{array}$ & $\begin{array}{l}\text { Model IV } \\
\text { Risks to partnerships }\end{array}$ \\
\hline $\begin{array}{l}\text { Use of AI applications to collect information in relation to } \\
\text { customers' online purchase history, types of online transac- } \\
\text { tions and digital footprint }\end{array}$ & $\begin{array}{l}-0.690 \\
(0.302)^{* *}\end{array}$ & $\begin{array}{l}-0.031 \\
(0.201)\end{array}$ & $\begin{array}{l}0.042 \\
(0.247)\end{array}$ & $\begin{array}{l}-0.491 \\
(0.470)\end{array}$ \\
\hline $\begin{array}{l}\text { Use of AI applications to offer personalised shopping sugges- } \\
\text { tions }\end{array}$ & $\begin{array}{l}-0.353 \\
(0.469)\end{array}$ & $\begin{array}{l}0.244 \\
(0.313)\end{array}$ & $\begin{array}{l}-0.940 \\
(0.307)^{* * *}\end{array}$ & $\begin{array}{l}-0.194 \\
(0.390)\end{array}$ \\
\hline Use of AI applications to target audience online & $\begin{array}{l}-0.944 \\
(0.286)^{* * *}\end{array}$ & $\begin{array}{l}-0.294 \\
(0.156)\end{array}$ & $\begin{array}{l}-0.375 \\
(0.177)^{* *}\end{array}$ & $\begin{array}{l}-0.348 \\
(0.258)\end{array}$ \\
\hline $\begin{array}{l}\text { Use of AI applications to offer immediate answers to custom- } \\
\text { ers }\end{array}$ & $\begin{array}{l}0.026 \\
(0.274)\end{array}$ & $\begin{array}{l}0.001 \\
(0.189)\end{array}$ & $\begin{array}{l}-0.186 \\
(0.215)\end{array}$ & $\begin{array}{l}-0.299 \\
(0.285)\end{array}$ \\
\hline Use of AI applications to offer cash flow forecasting & $\begin{array}{l}-0.768 \\
(0.384)^{* *}\end{array}$ & $\begin{array}{l}-0.264 \\
(0.241)\end{array}$ & $\begin{array}{l}-0.538 \\
(0.292)\end{array}$ & $\begin{array}{l}-0.364 \\
(0.337)\end{array}$ \\
\hline $\begin{array}{l}\text { Use of AI applications to collect information on other firms' } \\
\text { product assortments }\end{array}$ & $\begin{array}{l}-0.122 \\
(0.331)\end{array}$ & $\begin{array}{l}0.333 \\
(0.256)\end{array}$ & $\begin{array}{l}-0.309 \\
(0.264)\end{array}$ & $\begin{array}{l}-0.469 \\
(0.317)\end{array}$ \\
\hline Use of AI applications to combat fake product reviews & $\begin{array}{l}-0.096 \\
(0.554)\end{array}$ & $\begin{array}{l}0.396 \\
(0.319)\end{array}$ & $\begin{array}{l}0.054 \\
(0.345)\end{array}$ & $\begin{array}{l}0.080 \\
(0.465)\end{array}$ \\
\hline $\begin{array}{l}\text { Use of AI applications to protect data, customers' privacy and } \\
\text { strength cybersecurity }\end{array}$ & $\begin{array}{l}-0.547 \\
(0.423)\end{array}$ & $\begin{array}{l}-0.082 \\
(0.217)\end{array}$ & $\begin{array}{l}-0.061 \\
(0.234)\end{array}$ & $\begin{array}{l}0.296 \\
(0.321)\end{array}$ \\
\hline Use of AI applications for legal services & $\begin{array}{l}-0.338 \\
(0.388)\end{array}$ & $\begin{array}{l}0.343 \\
(0.187)\end{array}$ & $\begin{array}{l}-0.015 \\
(0.257)\end{array}$ & $\begin{array}{l}-0.226 \\
(0.357)\end{array}$ \\
\hline Use of AI applications for recruitment and HR activities & $\begin{array}{l}0.246 \\
(0.303)\end{array}$ & $\begin{array}{l}-0.363 \\
(0.295)\end{array}$ & $\begin{array}{l}-0.177 \\
(0.347)\end{array}$ & $\begin{array}{l}-1.017 \\
(0.425)^{* *}\end{array}$ \\
\hline Propensity to create new products & $\begin{array}{l}-0.083 \\
(0.037)^{* *}\end{array}$ & $\begin{array}{l}-0.086 \\
(0.022)^{* * *}\end{array}$ & $\begin{array}{l}-0.110 \\
(0.035)^{* * *}\end{array}$ & $\begin{array}{l}-0.092 \\
(0.042)^{* *}\end{array}$ \\
\hline Propensity to create new manufacturing processes & $\begin{array}{l}-0.065 \\
(0.043)\end{array}$ & $\begin{array}{l}-0.037 \\
(0.027)\end{array}$ & $\begin{array}{l}0.011 \\
(0.039)\end{array}$ & $\begin{array}{l}-0.034 \\
(0.046)\end{array}$ \\
\hline Propensity to create new business systems & $\begin{array}{l}-0.106 \\
(0.043)^{* *}\end{array}$ & $\begin{array}{l}-0.038 \\
(0.025)\end{array}$ & $\begin{array}{l}-0.088 \\
(0.037)^{* *}\end{array}$ & $\begin{array}{l}-0.150 \\
(0.042)^{* * *}\end{array}$ \\
\hline Propensity to adopt new manufacturing processes & $\begin{array}{l}-0.026 \\
(0.036)\end{array}$ & $\begin{array}{l}0.008 \\
(0.022)\end{array}$ & $\begin{array}{l}-0.009 \\
(0.032)\end{array}$ & $\begin{array}{l}0.023 \\
(0.044)\end{array}$ \\
\hline Propensity to adopt new business systems & $\begin{array}{l}-0.012 \\
(0.039)\end{array}$ & $\begin{array}{l}0.022 \\
(0.022)\end{array}$ & $\begin{array}{l}-0.064 \\
(0.036)\end{array}$ & $\begin{array}{l}0.035 \\
(0.037)\end{array}$ \\
\hline Years of operation & $\begin{array}{l}0.006 \\
(0.016)\end{array}$ & $\begin{array}{l}0.018 \\
(0.013)\end{array}$ & $\begin{array}{l}0.007 \\
(0.013)\end{array}$ & $\begin{array}{l}-0.012 \\
(0.016)\end{array}$ \\
\hline Medium enterprises $^{\wedge}$ & $\begin{array}{l}-0.055 \\
(0.425)\end{array}$ & $\begin{array}{l}0.079 \\
(0.231)\end{array}$ & $\begin{array}{l}-0.182 \\
(0.421)\end{array}$ & $\begin{array}{l}0.066 \\
(0.334)\end{array}$ \\
\hline Turnover^^ & $\begin{array}{l}-0.188 \\
(0.405)\end{array}$ & $\begin{array}{l}0.062 \\
(0.236)\end{array}$ & $\begin{array}{l}0.304 \\
(0.703)\end{array}$ & $\begin{array}{l}-0.166 \\
(0.371)\end{array}$ \\
\hline Gross assets $\wedge^{\wedge \wedge}$ & $\begin{array}{l}0.195 \\
(0.386)\end{array}$ & $\begin{array}{l}0.066 \\
(0.251)\end{array}$ & $\begin{array}{l}-0.197 \\
(0.580)\end{array}$ & $\begin{array}{l}0.146 \\
(0.441)\end{array}$ \\
\hline Wald test & $974.61 ; \mathrm{p}=0.000$ & $232.81 ; \mathrm{p}=0.000$ & $1118.62 ; \mathrm{p}=0.000$ & $665.63 ; p=0.000$ \\
\hline $\mathrm{R}^{2}$ & 0.618 & 0.371 & 0.659 & 0.559 \\
\hline Observations (n) & 592 & 592 & 592 & 592 \\
\hline
\end{tabular}

$\left(^{\wedge}\right)$ The reference category is small enterprises, i.e., less than 50 employees. Medium enterprises consist of 50 to 250 employees. $\left({ }^{\wedge}\right)$ More than 10 million (reference less than 10 million). $\left(^{\wedge \wedge}\right)$ More than 5 million (reference less than 5 million). Each model incorporates information on industry heterogeneity. Robust standard errors are reported in parentheses. (***) Statistically significant at the 1 per cent. (**) Statistically significant at the 5 per cent

a theoretical background to evaluate the study's hypothesis. The ILO's SMEs COVID-19 pandemic business risks scale (2020) measured business risks that SMEs could experience caused by the COVID-19 pandemic. A new scale was developed that captured whether SMEs utilise AI in their marketing, advertising, cash flow prediction, cyber-protection, and
HR services operations. The study outcomes indicated that business risks declined with the use of AI for both small and medium enterprises regardless of the turnover, gross assets, years of operation and level of innovativeness.

The study estimated that business risks caused by the COVID-19 pandemic reduced with the use of advertising 


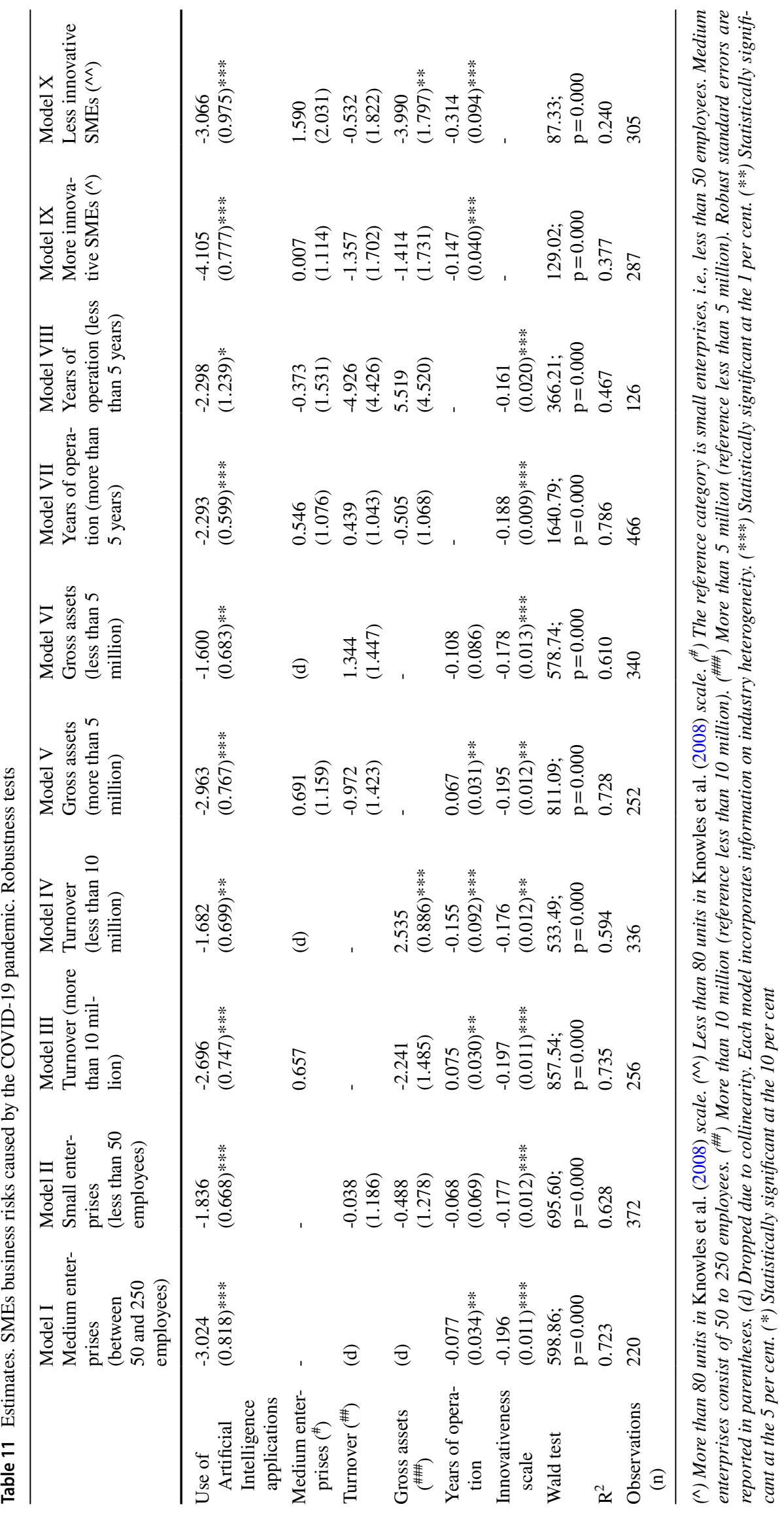


applications to target the audience online, applications to offer cash flow forecasting, and applications for recruitment and HR activities. During the COVID-19 pandemic, AI in advertising could help SMEs discover emerging trends, identify changes in consumer preferences, accommodating SMEs that adapt to these trends (Basri, 2021; Hansen \& Bøgh, 2021; Kumar \& Kalse, 2021). In addition, during the COVID-19 pandemic, AI pricing allowed SMEs to better determine cash flow, offering recommendations and predictions based on the business processes and the firms' financial condition (Basri, 2021; Hamal \& Senvar, 2021; Kumar \& Kalse, 2021). Furthermore, given that many employees may have to self-isolate during the COVID-19 pandemic, AI in HR services facilitated SMEs to analyse the staff required from a labour standpoint, enabling better planning and ensuring that the employees' time is dedicated to dealing with value-adding activities (Hansen \& Bøgh, 2021; Kumar $\&$ Kalse, 2021; Watney \& Auer, 2021).

In the present study, there were positive relationships between SMEs' financial performance, innovativeness, as well as the use and payoffs of AI applications. The literature indicated that SMEs' wealth and propensity to innovate and implement innovative technologies, such as AI, enhanced the digitisation of operations, improving performance and efficiencies, re-engineering business models, and ensuring business survival (Laudon \& Laudon, 2019). SMEs' capabilities to continually adjust based on their internal resources and environmental changes improved their competitiveness and performance (Breznik \& Hisrich, 2014; Felsberger et al., 2022; Helfat \& Peteraf, 2009).

If $\mathrm{AI}$ can be envisioned as a demonstration of best practices and/or innovativeness that boosts SMEs' operational effectiveness, adaptability, competitiveness, and economic growth, it will enable firms to develop defence mechanisms and define solutions against adversities imposed by COVID19 pandemic (Archibugi et al., 2013; Campbell et al., 2020; Laudon \& Laudon, 2019). During a crisis like COVID-19 pandemic, SMEs' performance reflects businesses' abilities to define strategies and develop capabilities to navigate new opportunities to innovate. The generativity of AI not only represents a method of achieving productivity benefits but also a fundamental innovation of the tools by which SMEs innovate (Ghobakhloo \& Ching, 2019; Kumar \& Kalse, 2021; Ulas, 2019).

\subsection{Theoretical implications}

A capacity to absorb and/or create knowledge and business systems constitutes a determining factor of continual improvement, and financial performance (Al Suwaidi et al., 2021; Chan, Teoh, et al., 2018; Chan, Morgan, et al., 2018; Davidsson, 2015; Shepherd \& Williams, 2018). Adoption of $\mathrm{AI}$ is the foundation of business competency and determines the direction of SMEs' evolution (Archibugi et al., 2013; Becheikh et al., 2006; Hanadi \& Aruna, 2013; OECD, 2020). In the present study, the theory of dynamic capabilities provided a framework to evaluate the impact of $\mathrm{AI}$ on the way SMEs use their resources to deal with the COVID19 pandemic's business challenges (Teece et al., 2016). AI could allow SMEs to form, extend, and modify their capabilities and build strategic assets helping them to enhance competitive positions. AI applications could enable SMEs to identify new opportunities or adapt systems for boosting performance and reducing business risks associated with the adverse business environment of the COVID-19 pandemic (Campbell et al., 2020; Canhoto \& Clear, 2020; Day \& Schoemaker, 2016; Teece et al., 2016).

During periods of business uncertainty, AI applications could boost SMEs sensing capabilities through a more efficient prediction of market trends and facilitation of customers' needs (Hercheui \& Ranjith, 2020). Moreover, during periods of economic instability, AI applications could enhance SMEs seizing capabilities through better-informed financial planning (Mendonça \& Andrade, 2018). In addition, in an unstable business environment, AI applications could enhance SMEs transformational capabilities through better-informed operational risks strategies (Hercheui \& Ranjith, 2020). Taken together, these enhanced capabilities will improve performance.

\subsection{Practical implications}

AI in SMEs cannot be quantitative assessed if there is uncertainty regarding how they are manifest in the empirical world. The proposed AI scale aimed to give information systems scholars an empirical assessment of the adoption of $\mathrm{AI}$ in SMEs. The proposed scale can summarise AI activity and assess business payoffs. Moreover, the proposed scale enabled to quantify whether the use of AI applications by SMEs as well as the number of AI applications in use by SMEs is associated with reduced business risks caused by the COVID-19 pandemic. Assessing whether SMEs utilise AI determines whether they engage with the trend toward digitalisation, with the dynamic capabilities theory providing a comprehensive base to examine the performance of the firms' digital transformation. To succeed in constantly changing, competitive, and digitally connected business environments, SMEs should explore and exploit new opportunities (Campbell et al., 2020; Chan et al., 2020) by adopting technology-enabled tools and networks to monitor how core technologies and markets are changing (Hercheui \& Ranjith, 2020). Due to resource constraints, SMEs seeking to invest in AI might need to search for, explore and exploit new external knowledge and available opportunities while also identifying existing firm knowledge. Chan et al. (2020) evaluated that small businesses can use common and 
inexpensive digital technologies to drive learning, innovation, and transformation.

The present study found that AI applications are associated with reduced business risks in both small and medium firms, hence, these findings and recommendations are relevant for managers of both small and medium firms. The study's insights could enable SMEs to better evaluate whether AI can support business operations during periods of uncertainty. The present study enabled to identify what types of AI applications could enhance dynamic capabilities and increase SMEs performance during the COVID-19 pandemic. During the COVID-19 pandemic, people stayed at home, consumers shifted from personal to digital interactions, and physical labour was restricted (Bartika et al., 2020; Donthu \& Gustafsson, 2020). AI could improve search results for online shoppers, enhance customer targeting, construct precise communications, and build conclusions as per their behaviours and boost customer services. Moreover, automated chat platforms could permit SMEs to scale their customer engagement and experience, freeing up the resources needed for more critical customer service, communication, and customer interactions (Jablonska \& Polkowski, 2017; Um et al., 2020).

$\mathrm{AI}$ in cash flow could facilitate SMEs to deal with liquidity issues and better simulate operations (Ivashchenko et al., 2020; Xinyue et al., 2020; Yan \& Ouyang, 2018; Yang et al., 2018). Moreover, AI applications to detect fraud and fake reviews could enable SMEs to better protect their operations and reputation (Hatfield, 2018; Jiang et al., 2016; Kumaravel \& Bizu, 2019; Mrabet et al., 2018). In addition, AI applications in repetitive HR and legal tasks could enable SMEs to effectively reduce labour-intensive processes, ensuring that the employees' time is dedicated to value-adding activities (Armour \& Sako, 2020; Black \& van Esch, 2020).

\subsection{Limitations and future research}

The study hypothesised that AI applications can reduce SMEs' business risks caused by the COVID-19 pandemic, utilising the theory of dynamic capabilities (Teece et al., 2016) to evaluate the potential association between AI and SMEs' performance during the COVID-19 pandemic. The present study assessed the combined effect of AI adoption in SMEs and AI in SMEs' sensing, seizing and transforming capabilities on SMEs performance. The empirical orientation of this study could not decompose the combined effect and did not have information to quantify SMEs' sensing, seizing and transforming capabilities, hence, did not empirically assess the relationship between $\mathrm{Al}$, sensing, seizing and transforming capabilities and SMEs' performance.
For instance, the present study did not quantify the level of SMEs' effectiveness in relation to operational routines and processes, internal competencies, business models and organisational practice. A new study should provide insights by empirically assessing the association between AI and organisational practices and how this can impact SMEs' performance. A mediation analysis would provide important insights (Bernroider et al., 2014; Hsu \& Wang, 2012). Moreover, the interaction between AI applications in use and innovativeness on SMEs' business risks caused by the COVID-19 pandemic was not examined. Future research might approach the association between $\mathrm{AI}$ and SMEs' performance from an alternative theoretical perspective, for instance, offer an innovation-oriented analysis (Al Suwaidi et al. 2021; Chan et al., 2020; Breznik \& Hisrich, 2014; Hanadi \& Aruna, 2013; Becheikh et al., 2006).

The present study involved data collected from a limited number of SMEs in a single region over a few months, so future studies should collect data from more SMEs from other regions over a longer period of time. Moreover, in the present study, although information on industries was included in the empirical specifications, an industry-oriented analysis was not conducted due to limited observations per industry. For robust generalisations, it remains of interest that new studies evaluate associations shared by AI and SMEs' performance per industry.

The present study developed a new scale examining whether SMEs utilised AI in their operations, so future studies should consider further AI applications and inform the scale. Importantly, the present study utilised the ILO's scale of SMEs' business risks caused by the COVID-19 pandemic, so further studies could examine connections shared by AI and SMEs' profitability and revenues during the COVID-19 pandemic. Moreover, for firm evaluations, there remains the need to examine associations between AI and firms' performance post-COVID-19 pandemic, as well as to consider whether the assigned patterns hold in large firms.

The present study did not assess whether SMEs generated their own AI systems or bought AI applications, so issues in relation to AI literacy as a source of competitive advantage for firms require examination (Wagner, 2021). Additionally, the technical characteristics (i.e., algorithms) of AI applications were not evaluated, future studies should quantify and examine the aforementioned considerations and offer insights by constricting a better-informed scale.

There remain concerns around the use of $\mathrm{AI}$ in business processes, including decision-making (Ivashchenko et al., 2020). Firms must ensure whether they are ready before bringing $\mathrm{AI}$ into their operations and counter the business shifts because of AI integration (Kumar et al., 2019). The 
literature emphasises that SMEs should be conscious that AI models require updating to capture the contemporary needs of firms, markets, and customers (Campbell et al., 2020). Optimal models require the collaboration of IT personnel, data scientists, and business personnel (Campbell et al., 2020). Firms must invest in staff who can extract meaning from data and identify ways to develop actionable insights for firms (Kumar et al., 2019).

Moreover, AI applications require monitoring to ensure compliance with anti-discrimination legislation and privacyrelated regulations, as well as data protection regulations (Campbell et al., 2020; Jablonska \& Polkowski, 2017; Newell \& Marabelli, 2015). Potentially, there exists a risk of firms losing control over the effective provision of functional and decision-making capabilities decision-making risks (Ivashchenko et al., 2020). AI systems require supervision to reduce mistakes, errors due to the lack of qualified staff, unreliable decision-making by AI systems, and destructive effect on the corporate culture (Campbell et al., 2020; Ivashchenko et al., 2020; OECD, 2019). Finally, AI applications may make job positions redundant as work performed traditionally by employees, such as contact centres and financial services, might be substituted by computers (Jablonska \& Polkowski, 2017; Korinek \& Stiglitz, 2018), hence there is a need for new studies to examine the implications of AI risks and misuse in SMEs.

\section{Conclusion}

A 10-item scale was developed to examine the use of AI in marketing, sales, communication, predictions, pricing and cash flow, fake reviews, cybersecurity, recruitment, and legal services, showing that SMEs' business risks caused by the COVID-19 pandemic declined with the use of AI applications in London, England. The outcomes proved robust across different specifications such as enterprise size, turnover, and years of operation, indicating that $\mathrm{AI}$ applications can help SMEs to adapt to unprecedented conditions during the COVID-19 pandemic. AI in SMEs can be envisioned as a set of best practices to boost their dynamic capabilities by leveraging technology to meet and exploit new opportunities and change operational processes, thereby increasing efficiency and reducing business risks caused by the COVID-19 pandemic.

\section{Appendix 1}

Scales

I. Artificial Intelligence Applications in Business ${ }^{\wedge}$

1. Our company uses AI applications to collect information in relation to customers' online purchase history, types of online transactions, and digital footprint

2. Our company uses AI applications to offer personalised shopping suggestions

3. Our company uses AI applications to target audience online

4. Our company uses AI applications to offer immediate answers to customers

5. Our company uses AI applications to offer cash flow forecasting

6. Our company uses AI applications to collect information on other firms' (competitors) product assortments, i.e., pricing, offers, sales, and PR activities

7. Our company uses AI applications to combat fake product reviews

8. Our company uses AI applications to protect data, customers' privacy, and improve cybersecurity

9. Our company uses AI applications for legal services

10. Our company uses AI applications for recruitment and HR activities

II. International Labor Organization's SMEs COVID-19 Pandemic Business Risks Scale (ILO, 2020)^ 
Scales

A. Risks to profits

1. COVID-19 disruptions are negatively impacting your clients and their ability to buy your products or services

2. Official government measures relating to health concerns for the overall population are negatively affecting your business sales

3. You have a high percentage of goods/services that serve non-domestic markets

4. These markets are located in medium to high-risk countries

5. There has been a decrease in sales to these markets

6. Disruptions are negatively impacting on your main suppliers and their ability to supply inputs to your enterprise

7. You have experienced disruptions in your supplies due to increased government restrictions

8. You have only one supply route to access your key suppliers

9. You do not have alternative suppliers that could provide goods and services in case of disruption

10. You rely heavily on foreign suppliers for most of the key inputs and raw materials needed for your business (over 75 per cent of key inputs)

11. There has been a rise in "societal" intolerance and prejudice as evidenced in the media, street demonstrations and political discourse, among others

12. The current media environment has negatively influenced the working environment

13. COVID-19 is impacting on economic activity that directly impacts your business or the markets you operate in or you expect it to

14. Unemployment rates are rising in the markets you operate in

15. There has been an increase in actual criminal activity or increased risk of criminal activity directed at your enterprise as a result of depressed economic activity

16. There has been a sudden increase in the price of inputs and other goods required to conduct your business operations

B. Risks to processes

17. You have faced difficulties accessing the necessary equipment and machinery to run your business from suppliers

18. There has been disruption or significant delays to support services that you need for maintenance of key equipment and machinery

19. Your business (e.g., workers, equipment and livestock) is neither partly nor fully insured

20. A high percentage of your raw materials are imported

21. You have experienced delays in securing raw materials/ necessary production inputs through ports

22. You have experienced difficulties in securing your key stock and raw materials

23. Your enterprise has been negatively impacted by increased government restrictions/demands (for example increased health checks delaying delivery of products coming/going from your premise)

24. Your main stocks and/or raw materials are located in only one location

C. Risks to partnerships

25.There has been significant or ongoing disruptions of key public utilities (water, electricity, telecoms, health and sanitation) that has negatively impacted your business or the markets you operate in

26. There has been significant or ongoing disruptions of key public utilities (water, electricity, telecoms, health and sanitation) that has negatively impacted your workers (i.e., sanitation facilities at home)

27. There has been negative or sudden change of the costs related to public utilities

28. There has been an increase in corruptive practices for access to public utilities or public infrastructure (such as health care)

29. COVID-19 disruptions are negatively impacting your competitors and their ability to remain competitive

30. There is limited or no scope to collaborate with competitors - to share health and safety practices/equipment

31. There is limited or no scope to collaborate with competitors -to share stock

32. There is limited or no scope to collaborate with competitors -to share equipment

33. It is more difficult to access finance or the behaviour of financial services providers (e.g., increased lending obligations, less choice of providers, etc.) is negatively impacting your enterprise operations

34. Restrictions to accessing public infrastructure have been put in place that negatively impacts your enterprise or the markets you operate in or your workers

35. There is increased costs of using key public infrastructure that negatively impacts your enterprise or the markets you operate in

36. There has been any negative or sudden change of regulations (i.e., laws and regulations) that negatively impacts your enterprise or the markets you operate in

37. There is an increased uncertainty in policy/regulatory environment that could negatively impact your enterprise or the markets you operate in

38. Has there been any negative or sudden change of regulations (i.e., laws and regulations) that negatively impacts on your workers?

39. The government has not yet introduced subsidies (e.g., rent or wage subsidies) that could help my business and workers during the COVID-19 outbreak

40. Measures such as "State of Emergency' or major restrictions on freedom of movement have been put in place or threatened to be put in place

41. My business does not have a contingency plan for situations of crises

D. Risks to people

42. There are current personal safety risks such as a high number of COVID-19 cases in the geographical area of your operations

43. It is physically unsafe for workers to come and go from the workplace (e.g., using shared public transport etc.)

44. There has been an increase in sick leave/absenteeism

45. Due to the nature of my business, it is not possible to re-arrange work so workers can work from home (telework)

46. You are experiencing difficulties sourcing sufficient sanitation facilities (washing facilities, sanitizers, hand gels, gloves, masks etc.)

47. Vehicles used for your business (e.g., delivery, staff movement) have not yet been fitted with sanitizers and processes for regular cleaning

48. Workers have increased care/family responsibilities due to school closure or sick family members

49. There have been cases of internal transmission of COVID-19 by staff members or their immediate family members

50. Workers are less motivated due to a stressful working environment resulting from measures taken to address COVID-19

51 . Workers are leaving their jobs because of potential or actual safety concerns and/or incidents

52. Discriminatory/stigmatization behaviour among workers have led to threats and intimidation of fellow workers

53. Close physical contact with customers/suppliers is necessary

54. Workers have experienced personal trauma such as death or sickness of family members as a result of COVID-19

55. Close proximity in the workplace is necessary for production/service delivery purposes

56. There is no staff member responsible for daily review of official advice on risks and recommendations in relations to COVID-19

57. There are no or few procedures to conduct self-inspections to identify hazards that could result in COVID-19 spreading (e.g., regular health and safety check-ups conducted)

58. There are no or few regular audits in your premises to identify current or emerging hazards (e.g., areas requiring frequent physical touch)

59. Workers are currently not provided with direct training (or access to training) on COVID-19 preparedness and basic measures to protect themselves and others

60. My business does not have a process for reporting to public health authorities any known or suspected instances of workers or the public confirmed with

COVID-19 on the business premises 
Scales

III. Firms Innovativeness (Knowles et al., 2008)^^

A. Propensity to create new products

1. Our company actively develops new products

2. Our company sees creating new products as critical to our success

3 . When it comes to creating new products, our company is far better than the competition

4. Over the past three years, our company has been better than before regarding developing

new products

5. Within our company, we are able to implement new product ideas from other parts of our organization

B. Propensity to create new manufacturing processes

6. Our company actively develops in-house solutions to improve our manufacturing

processes

7. Our company sees new manufacturing processes as critical to our success

8. When it comes to creating new processes, our company is far better than the competition

9. Over the past three years, our company has been better than before regarding developing new manufacturing processes

10 . Within our company, we are able to implement new manufacturing process ideas from

other parts of our organization

C. Propensity to create new business systems

11. Our company actively develops in-house information technology solutions

12. Our company actively develops in-house managerial approaches

13. Our company sees creating new business systems as critical to our success

14. When it comes to creating new business systems, our company is far better than the

competition

15. Within our company, we are able to implement new business systems ideas from other parts of the organization

D. Propensity to adopt new manufacturing processes

16. Our company tends to be an early adopter of new manufacturing processes

17. Our company actively seeks new manufacturing processes from outside this organization

18. Having the latest, most efficient manufacturing processes is critical for our success

19. Within our company, we are able to implement new manufacturing processes used by other organizations

20. Our company considers manufacturing ideas provided by external sources critical to our success

E. Propensity to adopt new business systems

21 . Our company tends to be an early adopter of new business systems

22 . Having the latest, most efficient business systems is critical for our success

23. Within our company, we are able to implement new business systems used by other

organizations

24. Our company considers business systems ideas provided by external sources as critical to

our success

25. Our company actively seeks new business systems from outside this organization

$\left(^{\wedge}\right)$ Each item is a dichotomous answer (Yes/No). $\left({ }^{\wedge}\right)$ Each item is assessed through a seven-point Likert scale (Strongly Disagree-Strongly Agree)

Acknowledgements I thank the Editors-in-Chief Professor Ram Ramesh and Professor H. Raghav Rao and the Guest Editor Dr Nisreen Ameen for their helpful advices and comments, which significantly improved previous versions of this study. The suggestions offered by the three anonymous reviewers have been immensely helpful. I appreciate the study's participants and the UK Academy for Information Systems. Members from the Centre for Pluralist Economics at Anglia Ruskin University and from Pembroke College at the University of Cambridge have provided fruitful insights during the design of this study. I appreciate the knowledge transfer and assistance from the Pembroke College Circle at the University of Cambridge. The knowledge transfer from the Meander Research Hub is greatly appreciated.

Funding This study was supported by funding from Anglia Ruskin University, UK.

Data availability The data appendix, codes and original software estimates have been provided to the Journal during the submission process.

Code availability The data appendix, codes and original software tables have been provided to the Journal during the submission process.

\section{Declarations}

Ethics The procedures used in this study adhere to the tenets of the Declaration of Helsinki. Approval was obtained from the ethics committee of Anglia Ruskin University, UK.

Conflicts of interest/Competing interests We have no conflict of interest to declare.

\section{References}

Akpan, I. J. Udoh, E. A. P., \& Adebisi, B. (2020). Small Business Awareness and Adoption of State-Of-The-Art Technologies inEmerging and Developing Markets, and Lessons from the COVID19 Pandemic. Journal of Small Business and Entrepreneurship. https://doi.org/10.1080/08276331.2020.1820185

Al Suwaidi F., Alshurideh M., Al Kurdi B., \& Salloum S. A. (2021). The Impact of Innovation Management in SMEs Performance: A Systematic Review. In A. E. Hassanien, A. Slowik, V. Snášel, H. El-Deeb \& F. M. Tolba (Eds.), Proceedings of the International Conference on Advanced Intelligent Systems and Informatics 
2020. AISI 2020. Advances in Intelligent Systems and Computing (Vol. 1261). Cham: Springer. https://doi.org/10.1007/978-3030-58669-0_64

Alarie, B., Niblett, A., \& Yoon, A. H. (2018). How Artificial Intelligence Will Affect the Practice of Law. University of Toronto Law Journal, 68, 106-124.

Andreß, H. J., Golsch, K., \& Schmidt, A. W. (2013). Applied Panel Data Analysis for Economic and Social Surveys. Berlin/Heidelberg: Springer.

Anshari, M., Almunawar, M. N., Lim, S. A., \& Al-Mudimigh, A. (2019). Customer Relationship Management and Big Data Enabled: Personalization and Customization of Services. Applied Computing and Informatics, 15(2), 94-101.

Archibugi, D., Filippetti, A., \& Frenz, M. (2013). Economic Crisis and Innovation: Is Destruction Prevailing Over Accumulation? Research Policy, 42(2), 303-314.

Armour, J., \& Sako, M. (2020). AI-Enabled Business Models in Legal Services: From Traditional Law Firms to Next-Generation Law Companies? Journal of Professions and Organization, 7(1), 27-46.

Bank of England. (2020). How Has Covid-19 Affected Small UK Companies? London: Bank of England.

Basri, W. (2021). Examining the Impact of Artificial Intelligence (AI)Assisted Social Media Marketing on the Performance of Small and Medium Enterprises: Toward Effective Business Management in the Saudi Arabian Context. International Journal of Computational Intelligence Systems, 13(1), 142-152.

Bartika, A. W., Bertrand, M., Cullenc, Z., Glaeserd, E. L., Lucac, M., \& Stanton, C. (2020). The Impact of COVID-19 on Small Business Outcomes and Expectations. PNAS, 117(30), 17656-17666.

Becheikh, N., Landry, R., \& Amara, N. (2006). Lessons from Innovation Empirical Studies in the Manufacturing Sector: A Systematic Review of the Literature from 1993-2003. Technovation, 26(5/6), 644-664.

Bengio, Y., Courville, A., \& Vincent, P. (2013). Representation Learning: A Review and New Perspectives. IEEE Transactions on Pattern Analysis and Machine Intelligence, 35(8), 1798-1828.

Courville, B. Y., \& A. and Vincent P. (2013). Representation Learning: A Review and New Perspectives. IEEE Transactions on Pattern Analysis and Machine Intelligence, 35(8), 1798-1828.

Bernroider, E. W. N., Wong, C. W. Y., \& Lai, K. H. (2014). From Dynamic Capabilities to ERP Enabled Business Improvements: The Mediating Effect of the Implementation Project. International Journal of Project Management, 32(2), 350-362.

Black, J. S., \& van Esch, P. (2020). AI-Enabled Recruiting: What is it and How Should a Manager Use It? Business Horizons, 63, 215-226.

Borch, O. J., \& Madsen, E. L. (2007). Dynamic Capabilities Facilitating Innovative Strategies in SMEs. International Journal of Technoentrepreneurship, 1(1), 109-125.

Brem, A., Viardot, E., \& Nylund, P. A. (2021). Implications of the Coronavirus (COVID-19) Outbreak for Innovation: Which Technologies Will Improve Our Lives? Technological Forecasting and Social Change, 163, 120451.

Breznik, L., \& Hisrich, R. D. (2014). Dynamic Capabilities vs. Innovation Capability: Are They Related? Journal of Small Business and Enterprise Development, 21(3), 368-384.

Camacho-Miñano, M. D. M., Segovia-Vargas, M. J., \& Pascual-Ezama, D. (2015). Which Characteristics Predict the Survival of Insolvent Firms? An SME Reorganization Prediction Model. Journal of Small Business Management, 53(2), 340-354.

Campbell, C., Sands, S., Ferraro, C., Tsao, H.-Y., \& Mavrommatis, A. (2020). From Data to Action: How Marketers can Leverage AI. Business Horizons, 63, 227-243.

Canhoto, A., \& Clear, F. (2020). Artificial Intelligence and Machine Learning as Business Tools: A Framework for Diagnosing Value Destruction Potential. Business Horizons, 63(2), 183-193.
Chamola, V., Hassija, V., Gupta, V., \& Guizani, M. (2020). A Comprehensive Review of the COVID-19 Pandemic and the Role of IoT, Drones, AI, Blockchain, and 5G in Managing its Impact. IEEE Access, 8, 90225-90265.

Chan, C. M. L., Teoh, S. Y., Yeow, A., \& Pan, G. (2018a). Agility in Responding to Disruptive Digital Innovation: Case Study of an SME. Information Systems Journal, 29(2), 436-455.

Chan, L., Morgan, I., Simon, H., Alshabanat, F., Ober, D., Gentry, J., Min, D., \& Cao, R. (2018). Survey of AI in Cybersecurity for Information Technology Management. IEEE Technology and Engineering Management Conference. Atlanta: TEMSCON.

Chan, Y. E., Krishnamurthy, R., \& Desjardins, C. (2020). TechnologyDriven Innovation in Small Firms. MIS Quarterly Executive, 19(1), 39-55.

Chung, M., Ko, E., Joung, H., \& Kim, S. J. (2018). Chatbot E-Service and Customer Satisfaction Regarding Luxury Brands. Journal of Business Research, 117, 1-9.

Clarke, K. A. (2005). The Phantom Menace: Omitted Variable Bias in Econometric Research. Conflict Management and Peace Science, 22(4), 341-352.

Close Brothers Invoice Finance. (2020). A Third of SMEs Already Use Artificial Intelligence. East Sussex: Close Brothers Invoice Finance.

Cortina, J. M. (1993). What is Coefficient Alpha? An Examination of Theory and Applications. Journal of Applied Psychology, 78(1), 98-104.

Dadteev, K., Shchukin, B., \& Nemeshaev, S. (2020). Using Artificial Intelligence Technologies to Predict Cash Flow. Procedia Computer Science, 169, 264-268.

Davenport, T. H., Guha, A., Grewal, D., \& Bressgott, T. (2020). How Artificial Intelligence Will Change the Future of Marketing. Journal of the Academy of Marketing Science, 48(1), 24-42.

Davidsson, P. (2015). Entrepreneurial Opportunities and the Entrepreneurship Nexus: A Re-Conceptualization. Journal of Business Venturing, 30(5), 674-695.

Davidsson, P., Recker, J., \& von Briel, F. (2018). External Enablement of New Venture Creation: A Framework. Academy of Management Perspectives, 34(3), 311-332.

Day, G. S., \& Schoemaker, P. J. H. (2016). Adapting to Fast-Changing Markets and Technologies. California Management Review, 58(4), 59-78.

DeVellis, R. F. (2003). Scale Development: Theory and Applications. Applied Social Research Methods Series. Thousand Oaks CA: Sage Publications.

Dörpinghaus, S. (2019). Artificial Intelligence in the Cybersecurity of German Small and Medium Sized Enterprises. Sao Paulo: Sao Paulo School of Business Administration.

Donthu, N., \& Gustafsson, A. (2020). Effects of COVID-19 on Business and Research. Journal of Business Research, 117, 284-289.

Drydakis, N. (2021). Mobile Applications Aiming to Facilitate Immigrants' Societal Integration and Overall Level of Integration, Health and Mental Health Does Artificial Intelligence Enhance Outcomes? Computers in Human Behavior, 117(April), 106661.

Eisenhardt, K. M., \& Martin, J. A. (2000). Dynamic Capabilities: What Are They? Strategic Management Journal, 21(10/11), $1105-1121$.

Enholm, I. M., Papagiannidis, E., Mikalef, P., \& Krogstie, J. (2021). Artificial Intelligence and Business Value: A Literature Review. Information Systems Frontiers. https://doi.org/10.1007/ s10796-021-10186-w

Ezrachi, A., \& Stucke, M. (2016). Virtual Competition: The Promise and Perils of the Algorithm-Driven Economy. Harvard University Press.

Fan, X., Ning, N., \& Deng, N. (2020). The Impact of the Quality of Intelligent Experience on Smart Retail Engagement. Marketing Intelligence and Planning, 38(7), 877-891. 
Felsberger, A. Qaiser, F. H., Choudhary, A., \& Reiner, G. (2022). The Impact of Industry 4.0 on the Reconciliation of Dynamic Capabilities: Evidence from the European Manufacturing Industries. Production Planning and Control, 33(2-3), 277-300.

Fiserv,. (2017). White Paper. Leveraging Artificial Intelligence in Cash Forecasting. Wisconsin: Fiserv.

Solutions, F. (2021). UK Businesses Investing in Artificial Intelligence to Help with COVID-19 Recovery. Fountech Solutions.

Garbellano, S., \& Da Veiga, M. D. R. (2019). Dynamic Capabilities in Italian Leading SMEs Adopting Industry 4.0. Measuring Business Excellence, 23(4), 472-483.

Gaspar, R., Pedro, C., Panagiotopoulos, P., \& Seibt, B. (2016). Beyond Positive or Negative: Qualitative Sentiment Analysis of Social Media Reactions to Unexpected Stressful Events. Computers in Human Behavior, 56, 179-191.

Gautier, A., Ittoo, A., \& Van Cleynenbreugel, P. (2020). AI Algorithms, Price Discrimination and Collusion: A Technological, Economic and Legal Perspective. European Journal of Law and Economics, 50, 405-435.

Ghobakhloo, M., \& Ching, N. T. (2019). Adoption of Digital Technologies of Smart Manufacturing in SMEs. Journal of Industrial Information Integration, 16, 100107.

Greenleaf, G., Mowbray, A., \& Chung, P. (2018). Building Sustainable Free Legal Advisory Systems: Experiences from the History of AI \& Law. Computer Law and Security Review, 34, 314-326.

Guo, H., \& Polak, P. (2021). Artificial Intelligence and Financial Technology FinTech: How AI Is Being Used Under the Pandemic in 2020. In A. Hamdan, A. E. Hassanien, A. Razzaque \& B. Alareeni (Eds.), The Fourth Industrial Revolution: Implementation of Artificial Intelligence for Growing Business Success. Studies in Computational Intelligence (Vol. 935, pp. 169-186). Cham: Springer. https://doi.org/10.1007/978-3-030-62796-6_9

Hamal, S., \& Senvar, O. (2021). Effectiveness of Machine Learning Classifiers in Detecting Financial Accounting Fraud for Turkish SMEs. International Journal of Computational Intelligence Systems, 14(1), 769-782.

Hamilton, R. H., \& Davison, H. K. (2018). The Search for Skills: Knowledge Stars and Innovation in the Hiring Process. Business Horizons, 61(3), 409e419.

Hanadi, A. L., \& Aruna, M. (2013). Technology Innovation for SME Growth: A Perception for the Emerging Economies. Journal of Economics and Sustainable Development, 4(3), 156-162.

Hansen, E. B., \& B $ø \mathrm{gh}, \mathrm{S}$. (2021). Artificial Intelligence and Internet of Things in Small and Medium-Sized Enterprises: A Survey. Journal of Manufacturing Systems, 58(B), 362-372.

Hatfield, J. M. (2018). Social Engineering in Cybersecurity: The Evolution of a Concept. Computer and Security, 73, 102-113.

Helfat, C. E., \& Peteraf, M. A. (2009). Understanding Dynamic Capabilities: Progress Along A Developmental Path. Strategic Organization, 7(1), 91-102.

Helfat, C. E., \& Peteraf, M. A. (2015). Managerial Cognitive Capabilities and the Microfoundations of Dynamic Capabilities. Strategic Management Journal, 36(6), 831-850.

Hercheui, M., \& Ranjith, R. (2020). Improving Organization Dynamic Capabilities Using Artificial Intelligence. Global Journal of Business Research, 14(1), 87-96.

Hsu, L.-C., \& Wang, C.-H. (2012). Clarifying the Effect of Intellectual Capital on Performance: The Mediating Role of Dynamic Capability. British Journal of Management, 23(2), 179-205.

Ikumoro, A. O., \& Jawad, M. S. (2019). Assessing Intelligence Conversation Agent Trends- Chatbots-AI Technology Application for Personalized Marketing. TEST Engineering and Management, $81,4779-4785$.

ILO. (2020). The Six-Step COVID-19 Business Continuity Plan for SMEs. International Labor Organization.
International Monetary Fund. (2020). World Economic OutlookUpdate. IMF.

Ivashchenko, T., Chornodid, I., \& Ivashchenko, A. (2020). The Business Assistant Service as One of the Promising Areas for the Adoption of AI Technologies in Enterprise. Business: Theory and Practice, 21(2), 588-597.

Jablonska, R. M., \& Polkowski, Z. (2017). Artificial Intelligence Based Processes in SMEs. Studies and Proceedings of Polish Association for Knowledge Management, 86, 13-23.

Jiang, M., Cui, P., \& Faloutsos, C. (2016). Suspicious Behavior Detection: Current Trends and Future Directions. IEEE Intelligent Systems, 31(1), 31-39.

Juergensen, J., Guimón, J., \& Narula, R. (2020). European SMEs Amidst the COVID-19 Crisis: Assessing Impact and Policy Responses. Journal of Industrial and Business Economics, 47, 499-510.

Katz, R., Jung, J., \& Callorda, F. (2020). Can Digitization Mitigate the Economic Damage of a Pandemic? Evidence from SARS. Telecommunications Policy, 44(10), 102044.

Keshavarz, F., Waheed, A. A., Rachdi, B., \& Alhajj, R. (2018). Review Spam Detection by Highlighting Potential Spammers and Diminishing their Effect. International Journal E-Business Research, 14(1), 1-23.

Kietzmann, J., Paschen, J., \& Rae Treen, E. (2018). Artificial Intelligence in Advertising: How Marketers Can Leverage Artificial Intelligence along the Consumer Journey. Journal of Advertising Research, 58(3), 263-267.

Kim, H. K., So, W. H., \& Je, S. M. (2019). A Big Data Framework for Network Security of Small and Medium Enterprises for Future Computing. Journal of Supercomputing, 75, 3334-3367.

Klein, V. B., \& Todesco, J. L. (2021). COVID-19 Crisis and SMEs Responses: The Role of Digital Transformation. Knowledge and Progress Management, 28(2), 117-133.

Knowles, C., Hansen, E., \& Dibrell, C. (2008). Measuring Firm Innovativeness: Development and Refinement of a New Scale. Journal of Forest Products Business Research, 5(5), 1-24.

Korinek, A., \& Stiglitz, J. (2018). Artificial Intelligence and Its Implications for Income Distribution and Unemployment. In A. Ajay, J. Gans, \& A. Goldfarb (Eds.), The Economics of Artificial Intelligence: An Agenda (pp. 349-390). University of Chicago Press.

Köse, U. (2017). Improving Content Marketing Processes with the Approaches by Artificial Intelligence. Ecoforum Journal, 6(1), 1-8.

Kreiser, P. M., Marino, L. D., Kuratko, D. F., \& Weaver, K. M. (2013). Disaggregating Entrepreneurial Orientation: The NonLinear Impact of Innovativeness, Proactiveness and Risk-Taking on SME Performance. Small Business Economics, 40(2), 273-291.

Kumar, A., \& Ayedee, N. (2021). Technology Adoption: A Solution for SMEs to Overcome Problems During COVID-19. Academy of Marketing Studies Journal, 25(1), 1-16.

Kumar, A., \& Kalse, A. (2021). Usage and Adoption of Artificial Intelligence in SMEs. Materials Today: Proceedings. https://doi.org/ 10.1016/j.matpr.2021.01.595

Kumar, V., Rajan, B., Venkatesan, R., \& Lecinski, J. (2019). Understanding the Role of Artificial Intelligence in Personalized Engagement Marketing. California Management Review, 61(4), $135-155$.

Kumaravel, T., \& Bizu, B. (2019). Convolutional Neural Network for Customer's Opinion on Amazon Products. International Journal of Recent Technology and Engineering, 8(3), 6634-6643.

Laaksonen, O., \& Peltoniemi, M. (2016). The Essence of Dynamic Capabilities and their Measurement. International Journal of Management Review, 20(2), 184-205.

Laudon, K. C., \& Laudon, J. P. (2019). Management Information Systems: Managing the Digital Firm. Harlow: Pearson Education Limited. 
Li, N., Du, S., Zheng, H., Xue, M., \& Zhu, H. (2018a). Fake Reviews Tell No Tales? Dissecting Click Farming in Content-Generated Social Networks. China Communications, 15(4), 98-109.

Li, L., Su, F., Zhang, W., \& Mao, J. Y. (2018b). Digital Transformation by SME Entrepreneurs: A Capability Perspective. Information Systems Journal, 28(6), 1129-1157.

Li, H. (2019). Special Section Introduction: Artificial Intelligence and Advertising. Journal of Advertising, 48(4), 333-337.

Lichtenthaler, U. (2019). An Intelligence-Based View of Firm Performance: Profiting from Artificial Intelligence. Journal of Innovation Management, 7(1), 7-20.

Lokman, A. S., \& Zain, J. M. (2010). Extension and Prerequisite: An Algorithm to Enable Relations Between Responses in Chatbot Technology. Journal of Computer Science, 6(10), 1212-1218.

McKelvie, A., \& Davidsson, P. (2009). From Resource Base to Dynamic Capabilities: An Investigation of New Firms. British Journal of Management, 20(S), 63-80.

McKinsey and Company. (2020). How the COVID-19 Crisis is Affecting UK Small and Medium-Size Enterprises. McKinsey and Company.

Menard, S. W. (2008). Handbook of Longitudinal Research: Design, Measurement, and Analysis. Elsevier.

Mendonça, C., \& Andrade, A. (2018). Dynamic Capabilities and Their Relations with Elements of Digital Transformation in Portugal. Journal of Information Systems Engineering and Management, 3(3), 23.

Morgan, S. L. (2013). Handbook of Causal Analysis for Social Research. Springer.

Mrabet, Z. E., El Mrabet, Z., Kaabouch, N. E., Ghazi, H., \& El Ghazi, H. (2018). Cyber-Security in Smart Grid: Survey and Challenges. Computers and Electric Engineering, 67, 469-482.

Netermeyer, R. G., Bearden, W. O., \& Sharma, S. (2003). Scaling Procedures: Issues and Applications. Sage Publications, Thousand Oaks.

Newell, S., \& Marabelli, M. (2015). Strategic Opportunities (and Challenges) of Algorithmic Decision-Making: A Call for Action on the Long-Term Societal Effects of 'Datification.' The Journal of Strategic Information Systems, 24(1), 3e14.

Niemimaa, M. (2015). Interdisciplinary Review of Business Continuity from An Information Systems Perspective: Toward an Integrative Framework. Communications of the Association for Information Systems, 37(4), 69-105.

Office for National Statistics (2020). Business Impact of COVID-19 Survey (BICS) Results. Newport: Office for National Statistics.

OECD. (2008). Handbook on Constructing Composite Indicators. Methodology and User Guide. Paris: OECD.

OECD. (2017). Algorithms and Collusion: Competition Policy in the Digital Age. OECD.

OECD. (2019). Artificial Intelligence in Society. OECD.

OECD. (2020). COVID-19 and Responsible Business Conduct. OECD.

Papadopoulos, T., Baltas, K. N., \& Baltac, M. E. (2020). The Use of Digital Technologies by Small and Medium Enterprises During COVID-19: Implications for Theory and Practice. International Journal of Information Management, 55, 102192.

Pardhan, S., \& Drydakis, N. (2021). Associating the Change in New COVID-19 Cases to GDP per Capita in 38 European Countries in the First Wave of the Pandemic. Frontiers in Public Health: Health Economics, 8, 582140.

Paschen, J., Wilson, M., \& Ferreira, J. J. (2020). Collaborative Intelligence: How Human and Artificial Intelligence Create Value Along the B2B Sales Funnel. Business Horizons, 63, 403-414.

Pedauga, L., Sáez, F., \& Delgado-Márquez, B. L. (2022). Macroeconomic Lockdown and SMEs: The impact of the COVID-19 Pandemic in Spain. Small Business Economics, 58, 665-688.

Pérez, P., De-La-Cruz, F., Guerrón, X., Conrado, G., Quiroz-Palma, P., \& Molina, W. (2019). "ChatPy: Conversational Agent for SMEs." In 2019 14th Iberian Conference on Information Systems and
Technologies (CISTI) (pp. 1-6). Coimbra: CISTI. https://doi.org/ 10.23919/CISTI.2019.8760624

Piccialli, F., di Cola, V., Giampaolo, F., \& Cuomo, S. (2021). The Role of Artificial Intelligence in Fighting the COVID-19 Pandemic. Information Systems Frontiers, 23, 1467-1497.

Pisano, G., \& Teece, D. (2007). How to Capture Value from Innovation: Shaping Intellectual Property and Industry Architecture. California Management Review, 50(1), 278-296.

Priyono, A., Moin, A., \& Putri, V. N. A. O. (2020). Identifying Digital Transformation Paths in the Business Model of SMEs during the COVID-19 Pandemic. Journal of Open Innovation: Technology, Market and Complexity, 6, 104.

Qin, X., \& Jiang, Z. (2019). The Impact of AI on the Advertising Process: The Chinese Experience. Journal of Advertising, 48(4), 338-346.

Rebón, F., Castander, I., Argandoña, J., Gerrikagoitia, J. K., \& AlzuaSorzabal, A. (2015). An Antifraud System for Tourism SMEs in the Context of Electronic Operations with Credit Cards. American Journal of Intelligent Systems, 5(1), 27-33.

Rekha, A. G., Abdulla, M. S., \& Asharaf, S. (2016). Artificial Intelligence Marketing: An Application of a novel Lightly Trained Support Vector Data Description. Journal of Information and Optimization Sciences, 37(5), 681-691.

Rostain, T. (2017). Robots Versus Lawyers: A User-Centered Approach. Georgetown Journal of Legal Ethics, 30, 559.

Salehi-Esfahani, S., \& Ozturk, A. B. (2018). Negative Reviews: Formation, Spread, and Halt of Opportunistic Behavior. International Journal of Hospitality Management, 74, 138-146.

Shabbir, J., \& Anwer, T. (2015). Artificial Intelligence and its Role in Near Future. Journal of Latex Class Files, 14(8), 1-11.

Shepherd, D. A., \& Williams, T. A. (2018). Spontaneous Venturing: An Entrepreneurial Approach to Alleviating Suffering in the Aftermath of a Disaster. MIT Press.

Sood, N. (2020). The Power of AI to Transform the Global SME Credit Landscape, in. S. Chishti, I. Bartoletti, A. Leslie, and. S. M. Millie, The AI Book: The Artificial Intelligence Handbook for Investors, Entrepreneurs and FinTech Visionaries (pp. 52-53). New Jersey: John Wiley and Sons.

Surendiran, R., Rajan, K. P., \& Sathish, K. M. (2010). Study on the Customer Targeting Using Association Rule Mining. International Journal on Computer Science and Engineering, 2(7), 2483-2484.

Sunday, C. E., \& Vera, C. C. E. (2018). Examining Information and Communication Technology (ICT) Adoption in SMEs: A Dynamic Capabilities Approach. Journal of Enterprise Information Management, 31(2), 338-356.

Teece, D. (2007). Explicating dynamic capabilities: The nature and microfoundations of (sustainable) enterprise performance. Strategy Management Journal, 28(13), 1319-1350.

Teece, D., Peteraf, M., \& Leih, S. (2016). Dynamic Capabilities and Organizational Agility: Risk, Uncertainty, and Strategy in the Innovation Economy. California Management Review, 58(4), 13-35.

Teece, D. (2018). Business Models and Dynamic Capabilities. Long Range Planning, 51(1), 40-49.

Teodorescu, H. N. L. (2014). Survey of IC\&T in Disaster Mitigation and Disaster Situation Management. In H. N. Teodorescu, A. Kirschenbaum, S. Cojocaru \& C. Bruderlein (Eds.), Improving Disaster Resilience and Mitigation - IT Means and Tools. NATO Science for Peace and Security Series C: Environmental Security (pp. 3-21). Dordrecht: Springer. https://doi.org/10.1007/ 978-94-017-9136-6_1

Ulas, D. (2019). Digital Transformation Process and SMEs. Procedia Computer Science, 158, 662-671.

Ulrich, P. Frank, V., \& Kratt, M. (2021). Adoption of Artificial Intelligence Technologies in German SMEs - Results from an Empirical Study. In S. Hundal, A. Kostyuk \& D. Govorun (Eds.), 
Corporate governance: A search for emerging trends in the pandemic times (Vol. 189, pp. 76-84). Dubai: PACIS. https://doi.org/ $10.22495 /$ cgsetpt 13

Um, T., Kim, T., \& Chung, N. (2020). How Does an Intelligence Chatbot Affect Customers Compared with Self-Service Technology for Sustainable Services? Sustainability, 12, 5119.

Yan, H., \& Ouyang, H. (2018). Financial Time Series Prediction Based on Deep Learning. Wless Personal Communications, 102(2), $1-8$.

Yang, Y., Kolesnikova, A., Lessmann, S., Ma, T. S., \& M-T. and Johnson, J. E. V. (2018). Can Deep Learning Predict Risky Retail Investors? A Case Study in Financial Risk Behavior Forecasting. European Journal of Operational Research, 283(1), 217-234.

Yang, X., Mao, S., Gao, H., Duan, Y., \& Zou, Q. (2019). Novel Financial Capital Flow Forecast Framework Using Time Series Theory and Deep Learning: A Case Study Analysis of Yu'e Bao Transaction Data. IEEE Access, 7, 70662-70672.

van Esch, P., Overton, L. R. A., \& Van Esch, L. J. (2014). Mass Media Social Marketing Campaigns: A Review. International Business Research, 7(6), 1-17.

Vishnoi, S. K., Bagga, T., Sharma, A., \& Wani, S. N. (2018). Artificial Intelligence Enabled Marketing Solutions: A Review. Indian Journal of Economics and Business, 17(4), 167-177.

Wagner, D. N. (2021). Economic AI Literacy: A Source of Competitive Advantage. In B. Christiansen \& T. Škrinjarić (Eds.), Handbook of Research on Applied AI for International Business and Marketing Applications (pp. 135-152). Hershey: IGI Global. https:// doi.org/10.4018/978-1-7998-5077-9.ch008

Wang, Y., \& Shi, X. (2011). Thrive, Not Just Survive: Enhance Dynamic Capabilities of SMEs Through IS Competence. Journal of Systems and Information Technology, 13(2), 200-222.

Wang, Z., Hou, T., Song, D., Li, Z., \& Kong, T. (2016). Detecting Review Spammer Groups Via Bipartite Graph Projection. Computer Journal, 59(6), 861-874.

Wang, W., Deng, S. T., \& C-W. and Pan, Y. (2019). Smart Generation System of Personalized Advertising Copy and Its Application to Advertising Practice and Research. Journal of Advertising, 48(4), 356-365.

Warner, K. S. R., \& Wäger, M. (2019). Building Dynamic Capabilities for Digital Transformation: An Ongoing Process of Strategic Renewal. Long Range Planning, 52, 326-349.

Watney, C., \& Auer, D. (2021). Encouraging AI adoption by EU SMEs. Progressive Policy Institute.
Woodcock, R. (2019). Personalized Pricing as Monopolization. Connecticut Law Review, 51(2), 1-63.

Wooldridge, J. M. (2010). Econometric Analysis of Cross Section and Panel Data (2nd ed.). The MIT Press.

Wu, Y, Ngai, EW. TWu., \& P. and Wu, C. (2020). Fake Online Reviews: Literature Review, Synthesis, and Directions for Future Research. Decision Support Systems, 132, 113280.

Xinyue, C., Zhaoyu, X., \& Yue, Z. (2020). Using Machine Learning to Forecast Future Earnings. Atlantic Economic Journal, 48, 543-545.

Zahra, S. A., Sapienza, H. J., \& Davidsson, P. (2006). Entrepreneurship and Dynamic Capabilities: A Review, Model and Research Agenda. Journal of Management Studies, 43(4), 917-955.

Zhuang, M., Cui, G., \& Peng, L. (2018). Manufactured Opinions: The Effect of Manipulating Online Product Reviews. Journal of Business Research, 87, 24-35.

Publisher's Note Springer Nature remains neutral with regard to jurisdictional claims in published maps and institutional affiliations.

Nick Drydakis is a Professor in Economics in the Faculty ofBusiness and Law at Anglia Ruskin University, where he directs the Centre forPluralist Economics. He is the Course Convenor for the Economics of Growth andDevelopment and the Economics of Inequality and Poverty at the University ofCambridge and an Academic Associate at Pembroke College at the University ofCambridge. He collaborates with the Centre for Science and Policy at theUniversity of Cambridge as an Academic Expert. Professor Drydakis is a ResearchFellow in the Institute of Labor Economics (Bonn) and Fellow in the GlobalLabor Organization (Essen). He is an Academic Editor at PLOS Global PublicHealth. Professor Drydakis has published on mobile applications, ArtificialIntelligence and social and health outcomes. He has published single authorarticles in widely renowned journals, including: the Industrial Relations: AJournal of Economy and Society; Computers in Human Behavior; Human Relations;Social Science and Medicine; and Journal of Vocational Behavior. ProfessorDrydakis has worked on EU and World Bank research programmes, such as the ProgressProgramme, Horizon 2020, European Territorial Cooperation Programme andKnowledge Platform Programme. 